\title{
Assessing the potential market for a progesterone contraceptive vaginal ring (PCVR) as a new contraceptive option in sub-Saharan Africa using needs-based market segmentation
}

\author{
Francis Obare \\ Population Council \\ Deepa Rajamani \\ Population Council \\ Saumya RamaRao \\ Population Council
}

Follow this and additional works at: https://knowledgecommons.popcouncil.org/departments_sbsr-rh

Part of the Demography, Population, and Ecology Commons, Family, Life Course, and Society Commons, International Public Health Commons, and the Women's Health Commons How does access to this work benefit you? Let us know!

\section{Recommended Citation}

Obare, Francis, Deepa Rajamani, and Saumya RamaRao. 2014. "Assessing the potential market for a progesterone contraceptive vaginal ring (PCVR) as a new contraceptive option in sub-Saharan Africa using needs-based market segmentation." New York: Population Council. 
ASSESSING THE POTENTIAL MARKET FOR A PROGESTERONE CONTRACEPTIVE

\author{
VAGINAL RING (PCVR) \\ AS A NEW CONTRACEPTIVE OPTION \\ IN SUB-SAHARAN AFRICA \\ USING NEEDS-BASED \\ MARKET SEGMENTATION
}

Francis Obare Deepa Rajamani Saumya RamaRao COUNCIL 


\section{Popurarion \\ Ideas. Evidence. Impact.}

The Population Council confronts critical health and development issues-from stopping the spread of HIV to improving reproductive health and ensuring that young people lead full and productive lives. Through biomedical, social science, and public health research in 50 countries, we work with our partners to deliver solutions that lead to more effective policies, programs, and technologies that improve lives around the world. Established in 1952 and headquartered in New York, the Council is a nongovernmental, nonprofit organization governed by an international board of trustees.

Population Council

One Dag Hammarskjold Plaza

New York, New York 10017

Tel: +1 2123390500

Fax: +12127556052

popcouncil.org

Suggested citation: Obare, F., D. Rajamani and S. RamaRao. 2014. Assessing the Potential Market for a Progesterone Contraceptive Vaginal Ring (PCVR) as a New Contraceptive Option in sub-Saharan Africa Using Needs-based Market Segmentation. New York: Population Council. 


\section{Table of Contents}

Acknowledgments...............................................................................................................

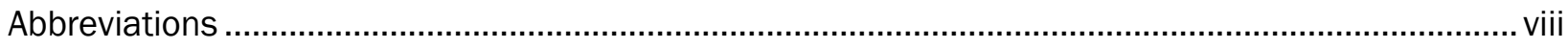

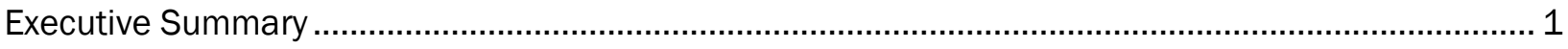

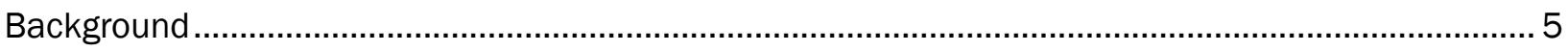

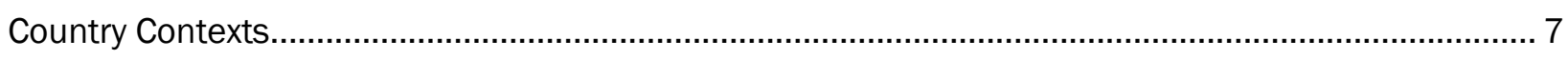

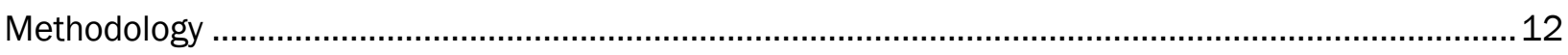

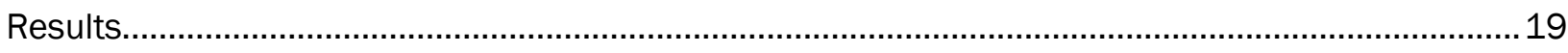

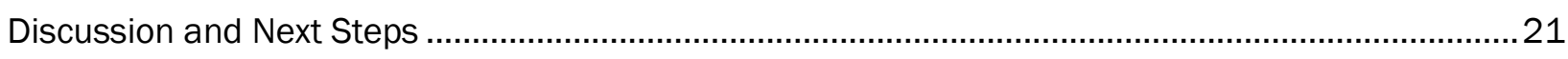

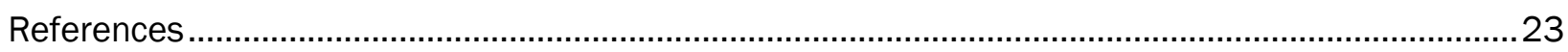




\section{LIST OF TABLES}

Table 1: Variations in the Proportion of Women Ages 15 to 49 Breastfeeding Four or More Times a Day, by Fertility Intentions, According to Background Characteristics

Table 2: Variations in the Proportion of Women Ages 15 to 49 Breastfeeding Four or More Times a Day Who Either Want to Delay Their Next Birth by One or More Years or Want No More Children After Resuming Sexual Activity, by Contraceptive Use According to Background Characteristics.

Table 3: Estimates of Potential PCVR Use with Simulated Uptake Scenarios....................................18

Table 4: Estimates of Annual Use for Each Market Segment in Kenya, Nigeria, and Sénégal..........20

Table 5: Appendix 1: Percent Distribution by Background Characteristics of Women Ages 15 to 49 in Kenya, Nigeria, and Sénégal

Table 6: Appendix 2: Variations in Breastfeeding Status by Background Characteristics Among Women Ages 15 to 49 in Kenya, Nigeria, and Sénégal..........................................26

Table 7: Appendix 3: Five Year Trends in Selected Indicators for Kenya, Nigeria, and Sénégal.......27 


\section{LIST OF FIGURES}

Figure 1: Family Planning Unmet Need in Kenya......................................................................

Figure 2: Family Planning Cost and Use in Kenya.........................................................................

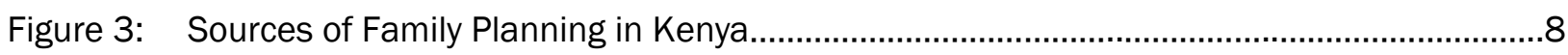

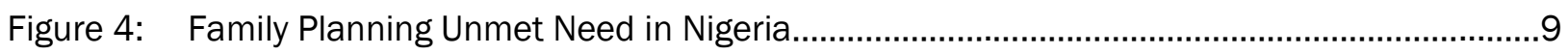

Figure 5: Family Planning Cost and Use in Nigeria........................................................................10

Figure 6: Sources of Family Planning in Nigeria........................................................................10

Figure 7: Family Planning Unmet Need in Sénégal.....................................................................11

Figure 8: Family Planning Cost and Use in Sénégal.....................................................................11

Figure 9: Sources of Family Planning in Sénégal..........................................................................11

Figure 10: Schematic Representation of Dimensions of Need and Use ..........................................13

Figure 11: Breastfeeding Distribution of Women Ages 15 to 49.................................................14

Figure 12: Distribution of Women Ages 15 to 49 by Breastfeeding Status and Future Childbearing

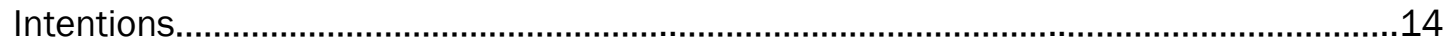

Figure 13: Distribution of Women Ages 15 to 49 by Breastfeeding Status, Postpartum Sexual Activity, Future Childbearing Intentions, and Current Contraceptive Use..........................16

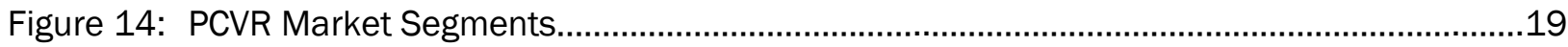




\section{Acknowledgments}

This study is part of a larger project funded by the Bill and Melinda Gates Foundation to provide a preliminary assessment of the Progesterone Contraceptive Vaginal Ring (PCVR)'s introduction as a new contraceptive option in sub-Saharan Africa. The project is being implemented by Population Council in Kenya, Nigeria, and Sénégal. We would like to thank our reviewers Aron Betru of Pledge Guarantee for Health and Janet Vail of PATH for their valuable suggestions for refining this report.

The data for this study are freely available to registered users from the MEASURE DHS website: www.measuredhs.com. MEASURE DHS is a program funded by the United States Agency for International Development (USAID) and implemented by ICF International to collect, analyze, and disseminate accurate and nationally representative data for developing countries' populations and health including HIV/AIDS and nutrition.

The opinions expressed in this report are those of the authors and do not necessarily reflect the views of its funding or implementing agencies. 


\section{Abbreviations}

\begin{tabular}{|c|c|}
\hline AIDS & Acquired Immunodeficiency Syndrome \\
\hline ANSD & Agence Nationale de la Statistique et de la Démographie, Sénégal \\
\hline CBS & Central Bureau of Statistics \\
\hline CPR & Contraceptive prevalence rate \\
\hline DHS & Demographic and Health Survey \\
\hline DRH & Department of Reproductive Health \\
\hline FP & Family planning \\
\hline HIV & Human Immunodeficiency Virus \\
\hline IUCD & Intrauterine contraceptive device \\
\hline KDHS & Kenya Demographic and Health Survey \\
\hline KNBS & Kenya National Bureau of Statistics \\
\hline LAM & Lactational amenorrhea method \\
\hline LAPM & Long-acting and Permanent Method \\
\hline MDA & Market development approaches \\
\hline $\mathrm{MoH}$ & Ministry of Health \\
\hline MoPHS & Ministry of Public Health and Sanitation \\
\hline NDHS & Nigeria Demographic and Health Survey \\
\hline NPC & National Population Commission \\
\hline PPFP & Postpartum family planning \\
\hline PCVR & Progesterone Contraceptive Vaginal Ring \\
\hline $\mathrm{RH}$ & Reproductive health \\
\hline RHSC & Reproductive Health Supplies Coalition \\
\hline SDHS & Sénégal Demographic and Health Survey \\
\hline TFR & Total fertility rate \\
\hline TMA & Total market approach \\
\hline US & United States \\
\hline USAID & United States Agency for International Development \\
\hline UNDESA & United Nations Department of Economic and Social Affairs \\
\hline WHO & World Health Organization \\
\hline WRA & Women of reproductive age \\
\hline WTP & Willingness to Pay \\
\hline
\end{tabular}




\section{Executive Summary}

Globally, over 65 percent of women in their first postpartum year express unmet need for family planning (FP). Developing countries, especially in sub-Saharan Africa, have disproportionately high unmet contraceptive needs compared to other regions, and their young women and new mothers have especially high levels of unmet need for spacing pregnancies. To address some of sub-Saharan Africa's barriers to effective contraception, there is renewed focus on new methods that offer greater ease of use. Common postpartum FP (PPFP) methods include progestin-only pills, injectable contraceptives, and intrauterine contraceptive devices (IUCDs). New methods under investigation would not require daily action, their use would be controlled by women themselves, and they would require no medical providers nor significant health system infrastructure for service delivery.

Contraceptive vaginal rings hold great potential by offering not only ease of use but a safe and effective FP solution as well. Population Council has developed a variety of vaginal rings for reproductive health (RH). The progesterone contraceptive vaginal ring or PCVR was designed by the Council and other scientists exclusively for lactating women’s PPFP. The PCVR is registered and sold under the brand name of Progering ${ }^{\circledR}$ in Central and Latin America. Taking advantage of sub-Saharan Africa's prolonged breastfeeding practices, the PCVR is designed exclusively for breastfeeding women and works seamlessly with the Lactational Amenorrhea Method (LAM) to further enhance LAM's pregnancy protection. In use in Latin America since 1998, the PCVR is now in clinical trials in India, and as part of its pre-introduction assessment in sub-Saharan Africa, Population Council, with funding from the Gates Foundation, is studying the potential market in Kenya, Nigeria, and Sénégal. The market segmentation analysis presented in this report will clarify the PPFP landscape in these three countries and aid PCVR's effective introduction with an emphasis on increasing access to those under-served.

This exercise's specific objectives are: 1) to estimate the proportion of PCVR consumers in each country (women aged 15 to 49) likely to use the method based on their fertility experiences and intentions, 2) to describe the segments of consumers through demographic and socio-economic characteristics, and 3) to forecast segment-specific PCVR use estimates by evaluating both current and future need for the product.

This report is based on secondary analysis of nationally representative Demographic and Health Survey (DHS) data for Kenya from 2008 to 2009, Nigeria in 2008, and Sénégal in 2005. The total number of women interviewed in their respective Surveys is 8,444 in Kenya, 33,385 in Nigeria, and 14,602 in Sénégal. Since need drives market behavior, a needs-based segmentation analysis was performed with the DHS data. Segmentation research is valuable for the PCVR because it permits definition of very specific needs-based market segments into which its entire consumer universe, both present and potential, can be discerned. The market segmentation analysis includes three steps and involves cross-tabulation.

The first step of analysis divided the sample of women of reproductive age (WRA) into those who are: 1) breastfeeding four or more times in a day; 2) would like to delay another child by one or more years; 3 ) have resumed sexual activity after childbirth but are not using any method of contraception; and 4) have resumed sexual activity and are using short-acting or barrier methods.

The second step described the segments identified in the first step with demographic and socio-economic characteristics including age, education, urban or rural residence, marital status, household wealth, children ever born, months since last birth, and participation in household decision-making.

The third step forecast PCVR use estimates for a potential user group by including non-breastfeeding womenwomen over 25 years old, with or without children-as well as the youngest women of reproductive age (15 to 25 years old) who will be first-time mothers in the near future. These women's potential need for PCVR is determined by their future childbearing intentions and intent to use contraception (if not using currently). While they are not part of PCVR's direct market, they can be considered future potential PCVR consumers. Four PCVR uptake scenarios are employed-a conservative five percent, moderate 10 percent, optimistic 15 percent, and ideal 20 percent-for simulating potential PCVR use. 
The major assumptions of this study are:

1) Indicators of need and use have not substantially changed since the last DHS.

2) Myths and misconceptions do not pose a significant barrier to PCVR use.

3) Women wanting to space their next pregnancy by more than one year may use PCVR during the first year and switch to other available methods thereafter; women looking to limit births can also use PCVR during their first postpartum year and switch to permanent methods thereafter.

In addition, it should be noted that cost barrier assessment for the PCVR is beyond the scope of this exercise.

\section{KEY FINDINGS}

The needs-based segmentation from this analysis provides a high degree of understanding of consumers' PPFP needs and yields three broad levels of need-partial, complete, and potential-and based on these levels of need, three PCVR consumer segments have been identified:

- Partial Need: This first segment, termed Easy Switchers include educated and urban women aged 20 to 29, from high wealth quintiles. These women can make independent decisions on their FP needs and are aware of method mixes available in their countries. Even though they currently use PPFP, they are most likely to be PCVR early adopters and are willing to switch to PCVR upon its introduction. As they already use a method, these women represent 'partial' need for a new PPFP method. While in Nigeria and Sénégal this segment includes urban, affluent women exclusively, in Kenya this segment includes an almost equal proportion of urban and rural women (as suggested by the high contraceptive prevalence) among the poorer and richer quintiles. This segment represents a potential PCVR user base of seven percent in Kenya and two percent each in Nigeria and Sénégal, or approximately 800,000 women in Kenya, 800,000 in Nigeria, and 69,000 women in Sénégal each year.

- Complete Need: The second segment referred to as Remote First-timers are uneducated, rural, and belong to the poorest households, and have never used PPFP. They will be introduced to PPFP for the first time with PCVR. Since they do not currently use FP, they represent 'complete' need for a new PPFP method and would benefit the most from PCVR's introduction. These hard-to-reach women present a huge PCVR opportunity, estimated at eight percent in Kenya (0.9 million women), 15 percent in Nigeria (6.1 million women), and 19 percent in Sénégal (0.7 million women) each year.

- Potential Need: Extending the PCVR consumer base to assess potential need, we include a third segment, Growth Feeders, who can be oriented to use the PCVR as a method that will serve their potential contraceptive needs and can become part of PCVR's future market. This segment includes nonbreastfeeding women (over age 25, with or without children) as well as the youngest women of reproductive age (15 to 25 years) who will mature into a group of new mothers with PPFP need in the future. Both of these groups can be considered future additions to the pool of potential PCVR consumers. This consumer group represents women with 'hidden' or potential future PPFP need vital for forecasting potential PCVR use. Using a conservative uptake estimate of 10 percent for this segment, we can calculate potential PCVR use estimates of two percent in Kenya, one percent in Nigeria, and two percent in Sénégal, which translates to roughly 200,000 women in Kenya, 400,000 women in Nigeria, and 69,000 women in Sénégal each year. While this segment may not be part of the direct marketing plan, it may be relevant from a future market development perspective. Learning more about the needs and attributes of this group will help PCVR's product positioning and messaging.

\section{IMPLICATIONS}

The three segments identified in this market segmentation demonstrate the opportunities for engaging multiple participants in PCVR's introduction, with a wider group of stakeholders including the public sector $(\mathrm{MoH})$, procurers (government and donors), and private sector (non-profit and commercial) benefitting from this exercise, identifying their segments of interest and tailoring specific strategies to serve them. 
- Easy Switchers present a straightforward targeting strategy. These urban, educated, and affluent FP users present the ideal PCVR introduction with minimal burden on marketing resources, as they are easily reached by technology such as mobile phones and other media. They are also most likely to influence PCVR's mode of introduction to their countries' method mixes by their ability and willingness to pay for PPFP. They can be served by their countries' private non-profit or commercial sectors. While this segment exclusively includes urban, affluent women in Nigeria and Sénégal, in Kenya it comprises almost equal proportions of urban and rural women (as suggested by the high contraceptive prevalence) among the poorer and richer quintiles. While affluent urban or rural dwellers can be served by the private commercial sector, the rural as well as urban poor must be served by the public and private non-profit sectors, which underscores the vital role of the Kenyan public sector in responding to the rapidly growing segment of poor urban women with FP needs.

- Remote First-timers require an extensive marketing strategy complete with compelling awareness campaigns and effective access strategies. These harder-to-reach rural women demand a systematic marketing approach with effective product messaging and access solutions. They will also prompt active public and private (non-profit) sector involvement in implementing PCVR price subsidization. The strong unmet need demonstrated by this segment will help justify the marketing investment and maximum resource allocation.

- The likelihood of PCVR's increased uptake regardless of CPR if both breastfeeding and non-breastfeeding women are targeted (Growth Feeders segment) suggests that potential PCVR consumer base will likely widen with appropriate awareness campaigns. The population growth rate of youth coupled with rapid urbanization in Kenya, Nigeria, and Sénégal indicates a potential surge in educated, first-time mothers who may be more receptive to new health technologies such as PCVR than previous generations, and who can also be easily reached with suitable access strategies. All the three sectors-public, private non-profit, and private commercial-have the potential to design innovative promotional strategies to nurture this growth segment. Analyzing this consumer segment is important for addressing key public sector decisions for program management, such as devising effective procurement plans and assessing governmental resource planning to facilitate future PCVR uptake. Catering to this segment will help empower young women to space their pregnancies safely and reduce chances of unintended pregnancies and abortion risks. It enables promotion of healthy postpartum care and breastfeeding practices according to WHO guidelines.

As potential next steps, we intend to build on this market segmentation exercise by identifying instruments for promoting PCVR use, from public or private sources, whichever is best positioned to serve these individual segments. Specifically, we will work on supplementing this exercise with the results from the ongoing PCVR acceptability studies in the three countries as well as other planned studies including the one assessing the consumers' 'Willingness to Pay' (WTP), which will provide more insights into PCVR consumer behavior-lifestyle, beliefs, and attitudes-to help us build the consumer archetypes and obtain realistic PCVR demand estimates. Along with this information, potential further enhancements include a more robust PCVR demand forecasting using detailed country UNFPA population projections and analyzing the growth trends in urban and rural populations in Kenya, Nigeria, and Sénégal. 


\section{Background}

Globally, about 222 million women aged 15 to 49 have an unmet need for modern family planning (FP) methods (Singh and Darroch 2012). Over 65 percent of women in their first postpartum year are included in this group. Women's FP needs vary over their reproductive life cycle, from pre-sexual adolescents to newly married young women wanting children, to mothers who desire healthy birth spacing, and finally, those who wish to limit their family size. Understanding and addressing these varying needs within these different stages is vital for designing effective FP solutions.

Developing countries, especially in sub-Saharan Africa, have disproportionately high levels of unmet need for contraception compared to other regions (Singh and Darroch 2012, Singh et al. 2009). Young women and new mothers in these countries in particular have a higher level of unmet need for spacing pregnancies compared to limiting child birth ${ }^{1}$. According to an analysis of Demographic and Health Surveys data from 27 countries, 95 percent of women who are as much as 12 months postpartum want to avoid a pregnancy within the following 24 months, but 70 percent do not use contraception (Ross and Winfrey 2001). While part of the challenge is women's limited use of contraception during their first six to 12 months postpartum, high discontinuation rates constitute another element, with about half of all users abandoning their methods within six months of first adoption (Ali et al. 2012, Bradley et al. 2009, Gebreselassie et al. 2008). Other factors contributing to the problem include lack of access to information and services, fear of side effects, prevalent FP myths and misconceptions, and cultural norms and beliefs that limit method acceptance and access (Campbell et al. 2006, Singh et al. 2009). Non-use and discontinuation of contraception lead to limited success in effective birth spacing and a high incidence of unwanted pregnancies, unsafe abortions, unplanned deliveries, and maternal mortalities. Postpartum family planning could prevent an estimated 30 percent and 10 percent of maternal and child mortalities, respectively (Cleland et al. 2006).

In countries like Kenya, Nigeria, and Sénégal, where there is a higher level of unmet need for spacing pregnancies, postpartum family planning (PPFP), primarily the first year following childbirth, requires safe and effective methods for both mothers and children. In these countries there is also a renewed focus on longacting methods, many of which are hormone-based. The World Health Organization (WHO), for example, considers long-acting and permanent family planning methods (LAPMs) as the most efficacious and costeffective contraceptive methods in the long run (WHO 2012). These include intrauterine contraceptive devices (IUCDs), implants, and voluntary surgical contraception (bilateral tubal ligation and vasectomy). In addition, new methods that offer greater ease of use, especially not requiring daily action, are women-controlled, and do not require medical providers and significant health system infrastructure for service delivery such as the contraceptive vaginal rings are likely to address some of the barriers to use (Darroch et al. 2011, Massai et al. 2000). Since breastfeeding is prolonged and widely practiced in these countries, early adoption of contraceptives following the birth of a child is likely to result in an overlap between contraceptive use and breastfeeding.

Responding to the global and national goals of expanding contraceptive choices, Population Council has developed many contraceptives, including vaginal rings. These rings serve a variety of FP needs in the reproductive life cycle of a woman, ranging from spacing needs during the postpartum period to spacing and limiting needs in the non-postpartum period. The first product developed in partnership with scientists globally was the progesterone contraceptive vaginal ring or PCVR, designed exclusively for the spacing needs of women in their first postpartum year. Taking advantage of the prolonged breastfeeding practices in the sub-Saharan region, the PCVR is intended exclusively for breastfeeding women and works seamlessly with the Lactational Amenorrhea Method (LAM) to further enhance the protection LAM offers.

${ }^{1}$ Demographic and Health Surveys from Kenya (2010), Nigeria (2009), and Sénégal (2010-11) 


\section{PCVR'S UNIQUE VALUE PROPOSITION}

The PCVR, as a postpartum family planning (PPFP) method, offers a unique value proposition in its design, use, and benefits:

- Design: A flexible ring, releasing very low dose of hormone, not interfering with sexual intercourse or quality of breast milk;

- Use: Completely user-controlled, offering discrete protection from pregnancy, convenient insertion and removal, non-interference with sexual activity, continuous use for up to three months without need for daily reminders;

- Benefits: Safe for mother and baby, enhances pregnancy protection offered by breastfeeding, offers worryfree option for new mothers to space pregnancies in a healthy way.

The PCVR has been in use in Latin America since 1998 and is under clinical trial in India (RHSC 2011). In Latin America, it has been sold commercially by pharmacists to consumers in Bolivia, Chile, Dominican Republic, Ecuador, Colombia, Guatemala, Honduras, and Peru (RHSC 2011) under the name Progering ${ }^{\circledR}$ and the market is now expanding to include Brazil and Mexico. Further details about the method are in Massai et al. (1999, 2000, 2005), Nath and Sitruk-Ware (2010), Sivin et al. (1997), and RHSC (2011). The availability of contraceptive methods such as the PCVR, immediately after delivery or during visits for postnatal care, is more likely to encourage new mothers to adopt a method quickly and empower them to achieve healthy spacing between child births.

As part of PCVR's pre-introduction assessment in sub-Saharan Africa, Population Council, with funding from the Gates Foundation, is studying PCVR's potential market in Kenya, Nigeria, and Sénégal to answer the questions: 1) What is PCVR's market size in the three countries; and 2) which groups of women are likely to use it? Understanding PCVR's potential market is, in turn, important for determining where the need for the method is greatest and how services can be delivered in a manner that yields the most efficient use of available resources for greatest impact.

To answer these questions, we use a well-known business technique called market segmentation to facilitate a better understanding of potential PCVR consumers and the market landscape. We employed a client-centric approach and conducted a needs-based market segmentation analysis to group the PCVR consumers based on a high-level assessment of their PPFP needs. By dividing the PCVR market into target consumer groups, we can serve the needs of these individual segments better and effectively convey the PCVR value proposition message by tailoring segment-specific marketing strategies.

\section{OBJECTIVES}

The overall objective of this exercise was to examine the potential market for PCVR in countries where Population Council is undertaking pre-introduction assessment i.e. Kenya, Nigeria and Sénégal. The specific objectives were:

- To divide the PCVR market into consumer groups by using a needs-based market segmentation approach;

- To describe the profile of the PCVR consumer segments using demographic, socio-economic and geographic attributes;

- To forecast segment-specific PCVR use estimates by evaluating both current and future need to use the product (using simulated projections for four potential uptake scenarios). 


\section{Country Contexts}

\section{KENYA}

Kenya had a population of 38.6 million people in 2009 equally distributed between women and men (50\% each) with women of reproductive age (15-49 years) comprising 48 percent of all women and 24 percent of the entire population (KNBS 2010). According to the 2008-2009 Kenya Demographic and Survey (KDHS), the total fertility rate (TFR) ${ }^{2}$ was 4.6 children per woman while the contraceptive prevalence rate (CPR) ${ }^{3}$ was 46 percent (KNBS and ICF Macro 2010). There were, however, marked variations in CPR by demographic and socio-economic characteristics. For instance, CPR was highest among women aged 30 to 34 and lowest among those 15 to 19 (55\% and 23\% respectively). It was also more than four times higher among women with secondary and higher education compared to those with none (60\% and $14 \%$ respectively) and nearly three times higher among women from the richest than those from the poorest households $(55 \%$ and $20 \%$ respectively). Similar patterns were noted with respect to regional variations. In particular, CPR was highest in Central Province and urban areas and was lowest in North Eastern Province and in rural areas $167 \%$ and $4 \%$ in Central and North Eastern provinces respectively; $53 \%$ and $43 \%$ in urban and rural areas, respectively; KNBS and ICF Macro 2010). Overall CPR was largely due to use of modern methods (39\%); hence variations in the use of modern methods mirrored those of the overall CPR. Family planning use in the postpartum period was much lower (25\%) than the overall CPR (KNBS and ICF Macro 2010, Gebreselassie et al. 2008).

\section{FIGURE 1: UNMET NEED FOR FAMILY PLANNING IN KENYA}

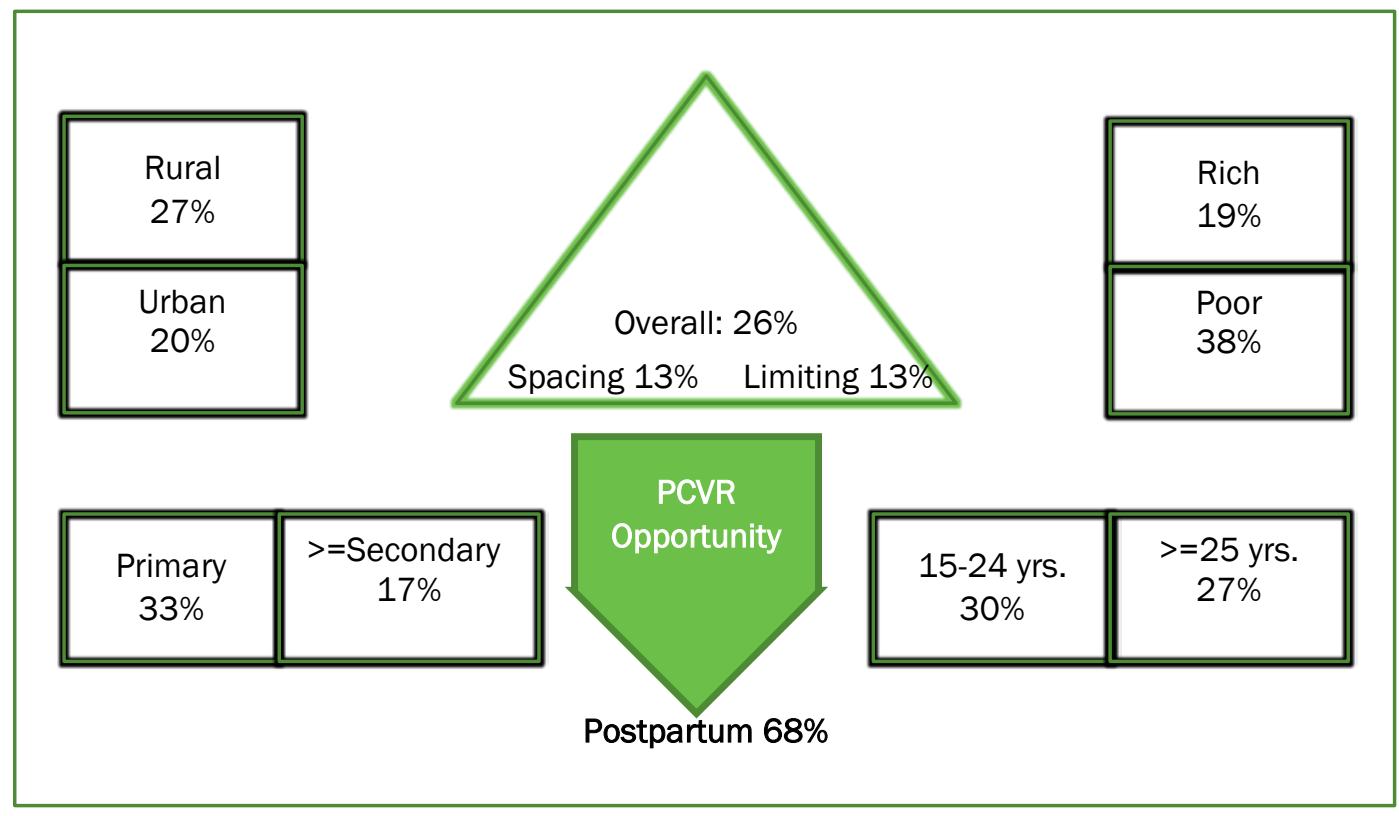

Source: KNBS and ICF Macro 2010

Kenya's unmet need ${ }^{4}$ was estimated in $2008-2009$ at 26 percent (13\% each for spacing and limiting births; KNBS and ICF Macro 2010). A detailed look at the various levels within this overall unmet need, shown in Figure 1, indicates equivalent need for both spacing and limiting births. The fact that unmet need is higher

\footnotetext{
2 TFR is the average number of children a woman would give birth to if her entire reproductive period is at prevailing age-specific fertility rates. ${ }^{3}$ Contraceptive prevalence rate is the percentage of currently married women using any method of contraception.

${ }^{4}$ Unmet FP need is the percentage of currently married women who either do not want any more children or want to wait two or more years before having another child but are not using contraception.
} 
among younger (aged 15 to 24 ) than older ( 25 and older) women (30\% and $27 \%$ among younger and older women, respectively) further suggests that understanding these young women's needs and tailoring specific programs to address them is of paramount importance. In addition, unmet need is higher in rural than urban areas; it was highest in Nyanza and lowest in Nairobi province (KNBS and ICF Macro 2010). It is important to note that postpartum unmet need $(68 \%)$ was more than twice as high than overall unmet need (KNBS and ICF Macro 2010, Gebreselassie et al. 2008). This strongly supports an opportunity for PCVR in Kenya's PPFP market. (Obare et al. (2012) includes further details about Kenya's FP policies, health system, and service delivery.)

Kenya's FP market provides a variety of methods-hormonal, IUCD, surgical, barrier, LAM, and fertility awareness (DRH/MoPHS 2010). Figure 2 illustrates the various methods used in Kenya, along with their costs, where applicable. Injectables, priced slightly less than US \$1 per unit, are clearly the most popular. Among women who pay for their method, median cost is highest for surgical contraception, about US $\$ 30$. Available methods for postpartum women include LAM, IUCDs, sterilization, progestin-only pills, injectables, and condoms, with injectables again being the most common (DRH/MoPHS 2010, Gebreselassie et al. 2008). Although the major sources of modern contraceptives for women are public health facilities (57\%), private health facilities account for a substantial 36 percent (Figure 3); other sources such as mobile clinics, community-based distribution, and shops comprise the remaining six percent (KNBS and ICF Macro 2010). Knowledge of Kenya's distribution model will enable us to formulate appropriate strategies for PCVR's marketing for each of these channels.

\section{FIGURE 2: FAMILY PLANNING COST AND USE IN KENYA}

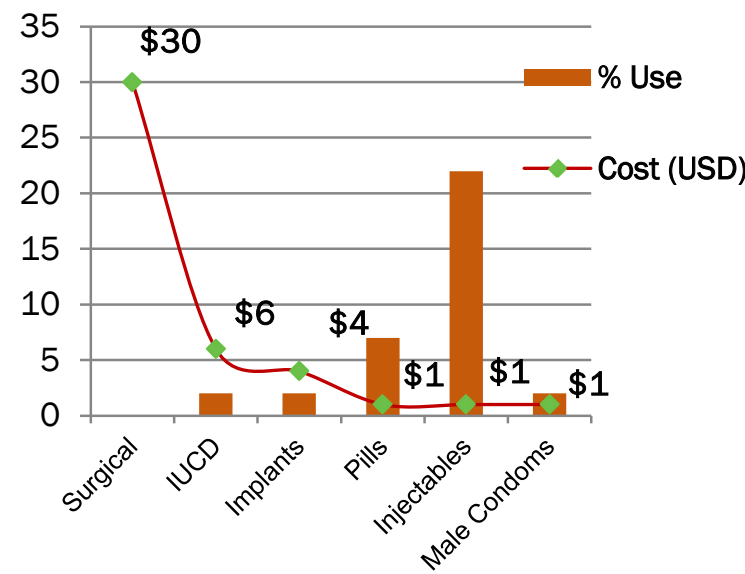

Source: KNBS and ICF Macro (2010)

\section{FIGURE 3: SOURCES OF FAMILY} PLANNING PRODUCTS IN KENYA

$$
\text { Vublic } \square \text { Private } \times \text { Other }
$$

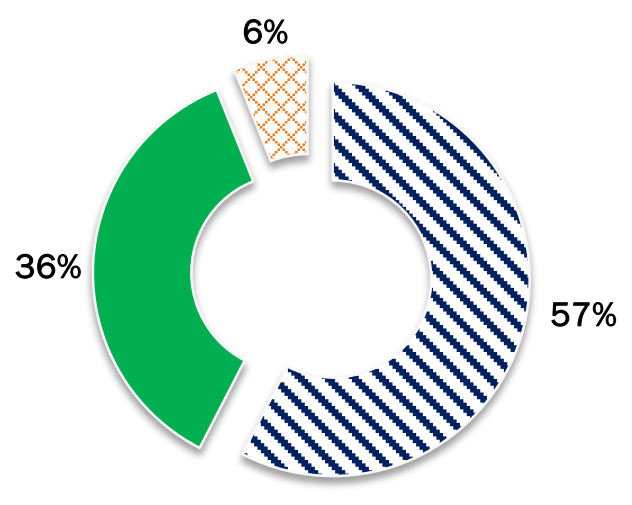

Source: KNBS and ICF Macro (2010)

\section{NIGERIA}

Nigeria's 2010 estimated population-158 million-was 49 percent female, with women of reproductive age comprising 47 percent of the female population and 23 percent of the entire population (UNDESA 2012). According to the 2008 Nigeria Demographic and Health Survey (NDHS), the country's TFR was 5.7 and CPR was 15 percent (NPC and ICF Macro 2009). Similar to Kenya, marked CPR variations exist according to demographic and socio-economic characteristics: CPR was highest for women ages 35 to 39 and lowest for those 15 to 19 (20\% and 3\%, respectively). CPR was also highest for women with higher than secondary education (37\%) as well as those from the richest households (35\%), and lowest for those with no education 
(7\%) as well as the poorest (3\%). CPR also varied widely by region, more than 10 times higher in the southwest than in the northwest (32\% and 3\%, respectively) and nearly twice as high in urban than rural areas (26\% and $9 \%$, respectively). CPR was largely driven by use of modern methods (10\%). Variations in modern method use, for demographic and socio-economic characteristics, are similar to those for overall CPR (NPC and ICF Macro 2009). Unlike Kenya, no major difference is found between postpartum contraceptive use (13\%) and overall CPR (Borda and Winfrey 2010).

Unmet FP need was 20 percent (15\% for spacing and 5\% for limiting) in 2008 with no major variations by agelowest among those aged 45 to 49 (16\%) and highest among those aged 20 to 24 and 30 to 39 (21\%). Figure 4 shows the breakdown of unmet need by various factors such as urban-rural residence, education levels, wealth status. It can be noted that the high level of postpartum unmet need (62\%), which is more than three times higher than the overall unmet need, directly indicates a huge opportunity for PCVR (Borda and Winfrey 2010).

\section{FIGURE 4: UNMET NEED FOR FAMILY PLANNING IN NIGERIA}

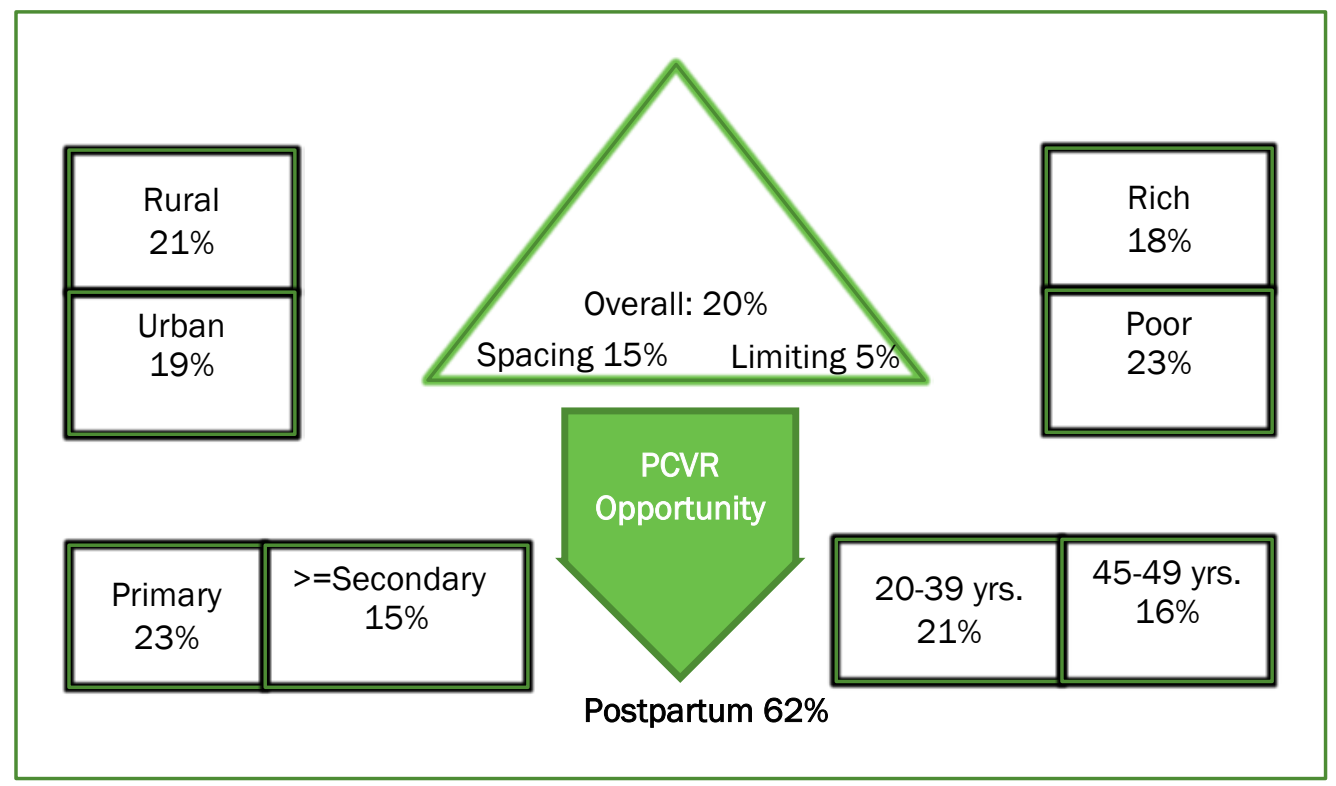

Source: NPC and ICF Macro 2009

Modern and traditional FP methods available in Nigeria include barrier methods (male and female condoms), IUCDs, combined oral pills, injectables, implants, female sterilization, LAM, rhythm method, withdrawal, and folk method (Ishaku and RamaRao 2012). The 2008 NDHS shows injectables as the most common method, followed by pills, as shown in Figure 5.

Available methods for postpartum women include injectables, condoms, progestin-only pills, LAM, with LAM the most commonly used during this period (Borda and Winfrey 2006). Unlike Kenya, it can be seen from Figure 6 that the major source of modern contraceptive methods for women in Nigeria was private health facilities followed by public health facilities and other sources such as shops at 13 percent (NPC and ICF Macro 2009). The 60 percent private sector presence in Nigeria's FP market indicates the opportunity for potential partnerships with this sector for PCVR's introduction. The median cost of modern contraceptives for women (as shown in Figure 5) who paid for the last method they obtained ranged from about US $\$ 62$ for surgical contraception to less than US \$1 each for pills and male condoms (NPC and ICF Macro 2009). (The country's FP programs, including the health system structure and service delivery, is described in detail in Ishaku and RamaRao, 2012.) 
FIGURE 5: FAMILY PLANNING COST AND USE IN NIGERIA

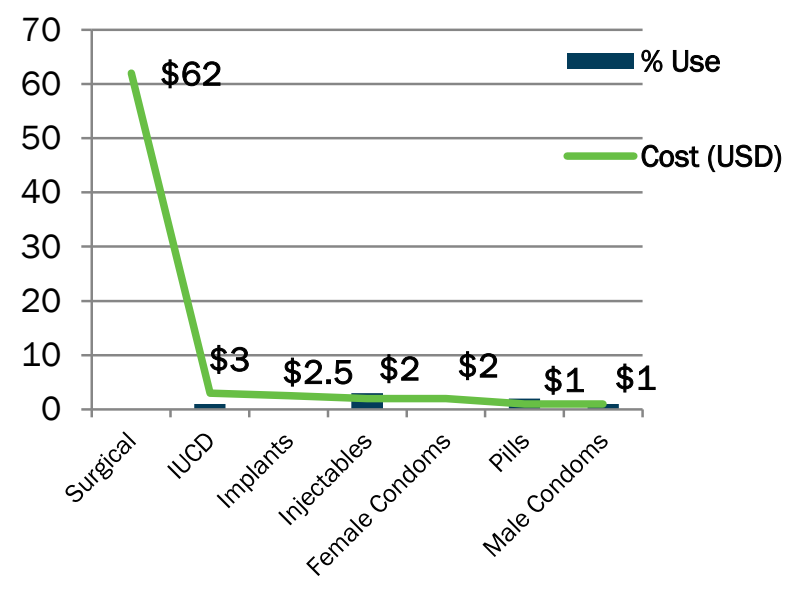

Source: NPC and ICF Macro (2009)
FIGURE 6: SOURCES OF FAMILY PLANNING PRODUCTS IN NIGERIA

Source: NPC and ICF Macro (2009)

\section{SÉNÉGAL}

Sénégal's population was estimated at 12.4 million in 2010, with similar proportions of males and females ( $50 \%$ each), while women of reproductive age comprise 48 percent of the female population and 24 percent of the entire population (UNDESA 2012). Estimates from the 2010-2011 Sénégal Demographic and Health Survey (SDHS) show TFR of 5.0, with CPR at 13 percent (ANSD and ICF International 2012). Similar to Kenya and Nigeria, CPR is higher in urban areas (22\% urban and $7 \%$ rural), among women with secondary and higher education than those with none ( $27 \%$ and $9 \%$, respectively), and among women from the richest than the poorest households (25\% and 5\%, respectively; ANSD and ICF International 2012). In addition, CPR was highest for women aged 40 to 44 (17\%), and among those from Ziguinchor and Saint Louis regions (18\% in each); CPR was lowest among women aged 15 to 19 (6\%) and those from Matam region (3\%). Similar to Kenya and Nigeria, overall CPR is largely due to the use of modern methods (12\%), and variations in the use of those methods are similar to those for overall CPR. Nonetheless, given the country's low CPR, it is likely that postpartum contraceptive use is equally low.

Overall unmet FP need in the country was 29 percent with higher unmet need for spacing (22\%) than limiting births (8\%). There were no major variations in unmet need for urban versus rural residence (30\% urban and $29 \%$ rural), education (28\% among those with secondary and higher educations to $31 \%$ among those with no education), or household wealth status ( $27 \%$ for women from richest to $32 \%$ for those from middle quintile households). However, unmet need was highest among women under 40 years of age (ranging from $30 \%$ to $31 \%$ ) and lowest among those aged 45 to 49 (20\%). Similarly, unmet need was highest in Kaolack and Fatick regions (34\%) and lowest in Sédhiou (23\%; ANSD and ICF International 2012). 


\section{FIGURE 7: UNMET NEED FOR FAMILY PLANNING IN SÉNÉGAL}

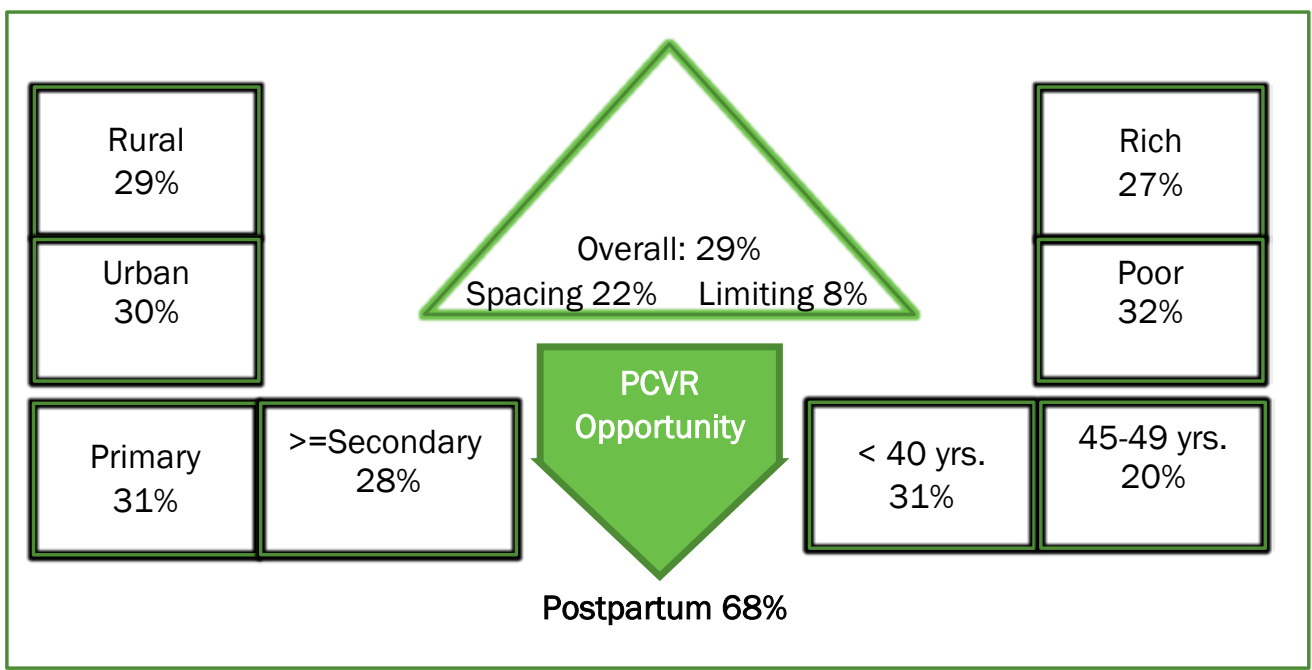

Source: ANSD and ICF International 2012

Although there are no recent estimates of Sénégal's unmet PPFP need, the patterns are likely similar to Kenya's and Nigeria's, with unmet PPFP need substantially higher than overall unmet need. Further details of Sénégal's FP programs including policy, health system structure, and service delivery are in Mané et al. (2012).

Available modern and traditional methods in Sénégal include barrier (male condom), IUCD, combined oral pill, injectable, implant, female sterilization, rhythm, and withdrawal methods. According to the 2010-2011 SDHS (Figure 8 ), injectables are the most common (5\%), followed by pills (4\%), with implants, IUCDs, and male condoms at one percent each (ANSD and ICF International 2012). According to contraceptive pricing data from ADEMAS $^{5}$, the median cost of pills is US $\$ 0.83, \$ 0.63$ for condoms, $\$ 2$ for injectables, and over $\$ 5$ for IUDs.

FIGURE 8: FAMILY PLANNING COST AND USE IN SÉNÉGAL

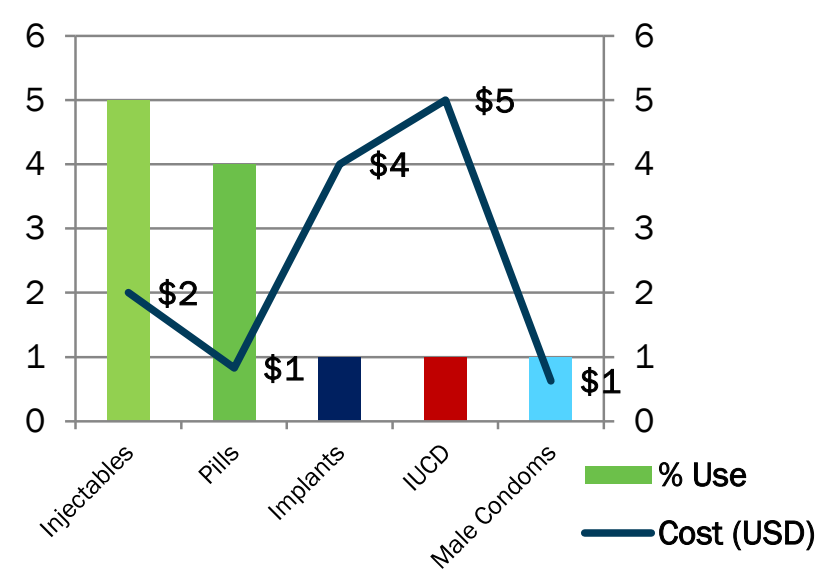

Source: ANSD \& ICF International 2012, ADEMAS

\section{FIGURE 9: SOURCES OF FAMILY PLANNING PRODUCTS IN SÉNÉGAL}

- Public $\quad$ Private I! Other

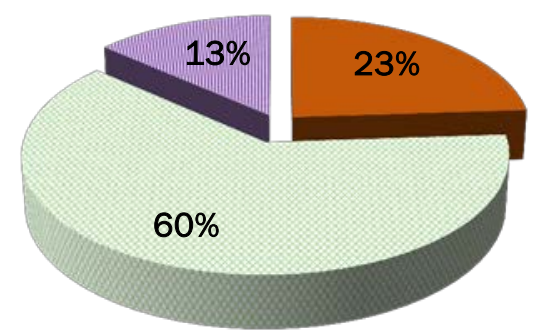

Source: ANSD \& ICF International 2012, ADEMAS

\footnotetext{
${ }^{5}$ ADEMAS: Agency for the Development of Social Marketing, is a Sénégalese non-profit organization created in 1998 from the Sénégalese
} project contraceptive social marketing (SOMARC) funded by the U.S. Agency for International Development (USAID). 


\section{Methodology}

\section{MARKET SEGMENTATION}

Market segmentation, a well-known business technique, has been widely used in reproductive health (RH) in recent years. According to the Reproductive Health Supplies Coalition's Market Development Approaches (MDA) Working Group (2009:2), "market segmentation is the process of dividing the total market into smaller subsets ... that have similar characteristics, needs or behaviors." Segmentation research is valuable for the PCVR because it permits definition of specific needs-based market segments into which its entire consumer universe, present and potential, can be divided.

Specifically, market segmentation:

- Identifies specific groups of women willing to embrace this new method (present and potential consumers);

- Divides PCVR's market into measurable sub-groups with distinct characteristics (or segment profiles) and provides practical information for marketing resource allocation;

- Tailors PCVR's unique value proposition message to the consumer segments, each identified by their most important needs;

- Creates a common strategy for public and private sector collaboration for different population segments.

We extended this approach to forecast potential PCVR use estimates by looking at patterns of need and use (both current and future). We identified and developed unique descriptive segment profiles that account for distinctive demographic, socio-economic, and behavioral characteristics of each consumer segment.

\section{Analytical approach}

Typically, market segmentation analysis utilizes statistical techniques such as cross-tabulations or cluster analysis to sort diverse populations (Berg 2000). This report employs cross-tabulations. For better and more efficient ways of serving the potential PCVR market, needs-based segmentation grouped the FP markets in Kenya, Nigeria, and Sénégal, focusing on women's PPFP needs, resulting in three broad levels of need-partial, complete, and potential. To obtain these segments, three steps were utilized (depicted in Figure 10):

1. First, the sample of women interviewed in the DHS was grouped by dimensions of need and use outlined by the MDA Working Group (2009). Dimensions of PCVR need and use include breastfeeding practices, postpartum sexual activity, future childbearing intentions, and current contraceptive use. Because PCVR is for lactating women, and its effectiveness increases with breastfeeding intensity, women were grouped by whether they: 1) breastfed four or more times a day; 2) would like to delay having another child by at least one year, or want no more children; 3) resumed sexual activity after childbirth and were using short-acting or barrier methods 6 ; or 4) resumed sexual activity but were not using any contraceptive method.

2. The second step identified and described PCVR's consumer segments based on demographic and socioeconomic characteristics including age, education, urban or rural residence, marital status, household wealth, children ever born, months since last birth, and participation in household decision-making.

3. As a third step, we forecast PCVR use estimates for a potential user group by including non-breastfeeding women-women over 25 with or without children as well as the youngest women of reproductive age (15 to 25 years old) who will be first-time mothers in the near future. Their potential need for PCVR is determined by their future childbearing intentions and future intent to use contraception if not using currently. While not part of PCVR's direct market, both groups are part of a growth segment that can be considered future potential PCVR consumers. We present four PCVR uptake scenarios-a conservative five percent, moderate 10 percent, optimistic 15 percent, and ideal 20 percent-to simulate potential PCVR use.

${ }^{6}$ Short-acting methods include pills, injectables, rhythm, withdrawal, lactational amenorrhea methods, periodic abstinence, and foam/jelly while barrier methods include condoms (male or female) and diaphragm. 
FIGURE 10: SCHEMATIC REPRESENTATION OF DIMENSIONS OF NEED AND USE

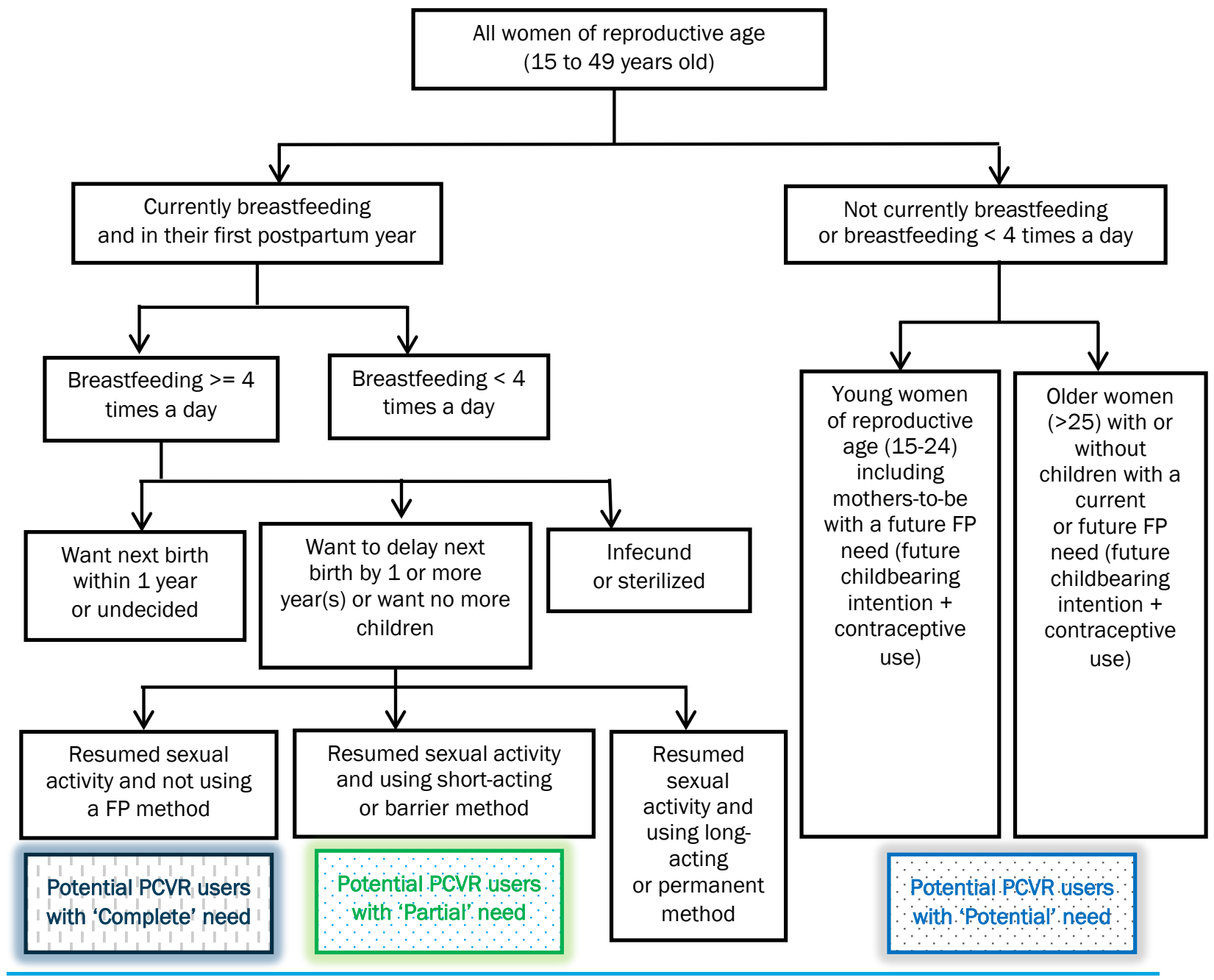

\section{Data sources and analysis}

Secondary data were analyzed from the Demographic and Health Surveys (DHS) for Kenya in 2008-2009, Nigeria in 2008, and Sénégal in 2005. The latest DHS data were used for Kenya and Nigeria, but 2005 data were used for Sénégal because its 2010-2011 Survey asked no detailed questions on breastfeeding frequency. A nationally representative probability-based sample of women of reproductive age (ages 15 to 49), the DHS collects information on basic demographic and socio-economic characteristics including childbearing experiences and intentions, FP method awareness and use, maternal and child health, mortality, as well as HIV/AIDS and other sexually transmitted infection awareness and behavior. In Kenya 8,444 women were interviewed, with 33,385 in Nigeria, and 14,602 in Sénégal. Table 5 (Appendix 1) provides the distribution of women interviewed by background characteristics. In all three countries, most women were between 20 and 29 years old, rural, with primary educations, married or living with someone, with one to four children.

\section{Breastfeeding status}

Figure 11 presents the distribution of women in Kenya, Nigeria, and Sénégal by their breastfeeding status at the time of the survey (not breastfeeding, breastfeeding less than four times a day, and breastfeeding four or more times a day). Overall, the proportion of women breastfeeding at the time of the survey was 24 percent in Kenya and 26 percent in both Nigeria and Sénégal. The proportion of women breastfeeding four or more times daily at the time of the survey was 22 percent in Kenya and 25 percent each in Nigeria and Sénégal. 
FIGURE 11: BREASTFEEDING DISTRIBUTION OF WOMEN AGES 15 TO 49

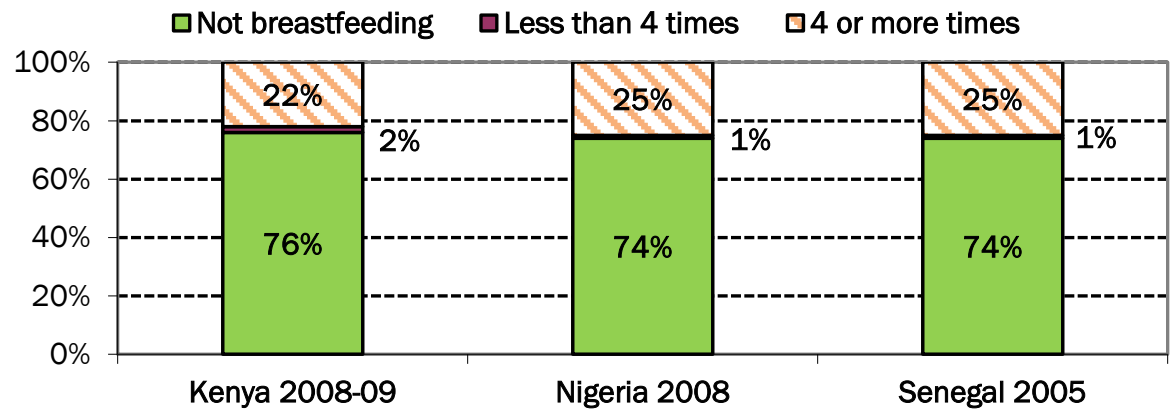

Variations in the proportions of women breastfeeding four or more times a day, according to background characteristics, are presented in Table 6 (Appendix 2). In all three countries, the highest proportions of women breastfeeding four or more times were among those aged 20 to 29, rural, with no education, from the poorest households, married or living with someone, with their most recent birth within 12 months preceding the Survey. In addition, women in Kenya and Nigeria with one or two children were more likely to breastfeed four or more times a day compared to those with three or more children. In Sénégal, the highest proportion of women breastfeeding four or more times a day was among those with three or four children. The proportions of women in Kenya and Nigeria that breastfed four or more times were higher among those reporting participating in household decision-making than among those who did not. In Sénégal, the proportion was higher among those who reported not participating in household decision-making than among those who did (Table 6).

Breastfeeding status and fertility intentions

FIGURE 12: DISTRIBUTION OF WOMEN AGES 15 TO 49 BY BREASTFEEDING STATUS AND FUTURE CHILDBEARING INTENTIONS

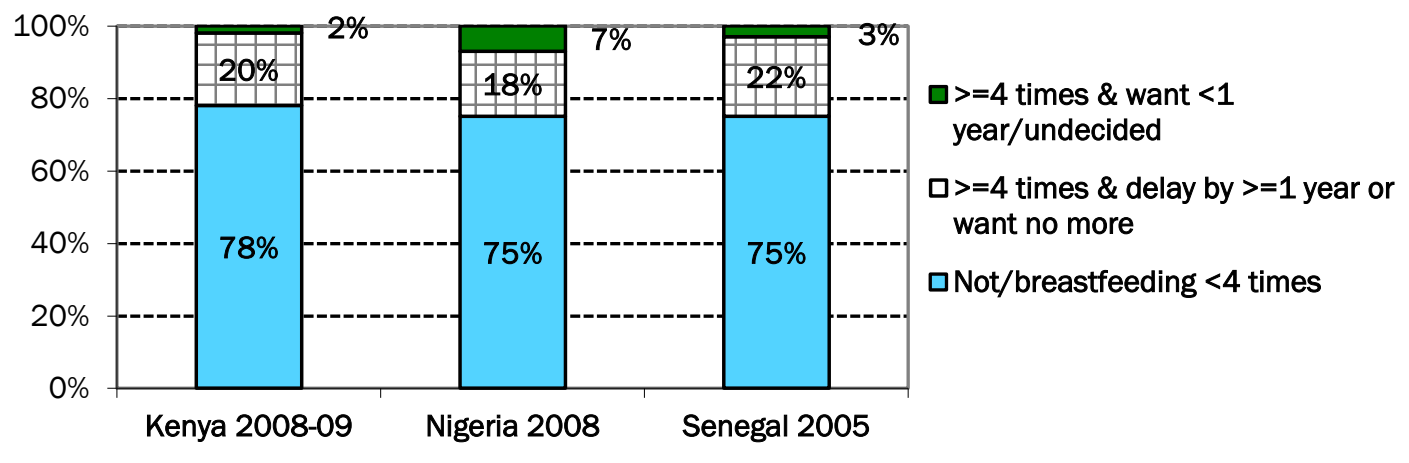

Breastfeeding status alone may not determine whether a woman is likely to use PCVR. Use of contraception is also influenced by future fertility intentions. Figure 12 presents the distribution of women by both breastfeeding status and future childbearing intentions. The proportion of women who breastfed four or more times a day and wanted to delay their next birth by at least one year or wanted no more children was 20 percent in Kenya, 18 percent in Nigeria, and 22 percent in Sénégal. In all three countries, these proportions were higher than those for women who were breastfeeding four or more times a day and wanted their next birth within one year, or were still undecided about the timing of their next birth. 
Table 1 shows the variations in the proportions of women who breastfed four or more times a day and either wanted to delay their next birth by at least one year or wanted no more children, along with background characteristics. Similar to breastfeeding status, the proportions of women that breastfed four or more times and either wanted to delay their next birth by at least one year or wanted no more children were highest among those aged 20 to 29, with no education, in rural areas, from the poorest households, married or living with someone, and with their most recent birth within 12 months preceding the survey, in all the three countries. Within and cross-country variations by the number of children ever born and participation in household decision-making are also similar to those of breastfeeding status noted in the previous section.

\section{TABLE 1: VARIATIONS IN THE PROPORTION OF WOMEN AGES 15 TO 49 BREASTFEEDING FOUR OR MORE TIMES A DAY, BY FERTILITY INTENTIONS, ACCORDING TO BACKGROUND CHARACTERISTICS}

\begin{tabular}{|c|c|c|c|c|c|c|}
\hline & \multicolumn{2}{|c|}{ Kenya (2008-09) } & \multicolumn{2}{|c|}{ Nigeria (2008) } & \multicolumn{2}{|c|}{ Sénégal (2005) } \\
\hline Characteristics & $\begin{array}{r}\text { Want to } \\
\text { delay by } \\
1+\text { years } \\
\text { or want no } \\
\text { more }\end{array}$ & $\begin{array}{r}\text { Want }<1 \\
\text { year } \\
\text { or } \\
\text { undecided }\end{array}$ & $\begin{array}{r}\text { Want to } \\
\text { delay by } \\
1+\text { years } \\
\text { or want no } \\
\text { more }\end{array}$ & $\begin{array}{r}\text { Want }<1 \\
\text { year } \\
\text { or } \\
\text { undecided }\end{array}$ & $\begin{array}{r}\text { Want to } \\
\text { delay by } \\
1+\text { years } \\
\text { or want no } \\
\text { more }\end{array}$ & $\begin{array}{r}\text { Want }<1 \\
\text { year } \\
\text { or } \\
\text { undecided }\end{array}$ \\
\hline \multicolumn{7}{|l|}{ Age (years) } \\
\hline$<20$ & 8.2 & 1.4 & 8.1 & 3.8 & 8.0 & 1.8 \\
\hline $20-29$ & 30.0 & 3.0 & 24.2 & 8.8 & 30.1 & 5.2 \\
\hline $30-39$ & 23.7 & 1.9 & 22.0 & 8.9 & 30.5 & 3.6 \\
\hline $40-49$ & 6.3 & 0.0 & 7.5 & 3.5 & 9.8 & 0.5 \\
\hline \multicolumn{7}{|l|}{ Highest education level } \\
\hline No schooling & 26.4 & 6.3 & 22.7 & 11.4 & 26.4 & 3.8 \\
\hline Primary & 22.7 & 1.8 & 20.7 & 6.8 & 18.2 & 2.8 \\
\hline Secondary & 14.2 & 1.0 & 12.7 & 3.7 & 9.5 & 2.0 \\
\hline Higher & 11.2 & 1.0 & 9.4 & 2.0 & 2.4 & 0.0 \\
\hline \multicolumn{7}{|l|}{ Place of residence } \\
\hline Urban & 13.0 & 1.4 & 14.1 & 4.7 & 15.4 & 2.3 \\
\hline Rural & 22.2 & 2.1 & 19.5 & 8.2 & 27.7 & 4.1 \\
\hline \multicolumn{7}{|l|}{ Wealth quintile } \\
\hline Poorest quintile & 31.3 & 3.9 & 23.6 & 11.4 & 32.5 & 4.7 \\
\hline Poorer quintile & 23.3 & 2.3 & 21.1 & 10.2 & 27.7 & 4.7 \\
\hline Middle quintile & 18.2 & 1.7 & 17.3 & 6.9 & 24.0 & 3.8 \\
\hline Richer quintile & 17.9 & 1.6 & 15.0 & 4.8 & 17.4 & 2.5 \\
\hline Richest quintile & 13.2 & 0.7 & 12.5 & 2.5 & 11.9 & 1.4 \\
\hline \multicolumn{7}{|l|}{ Marital status } \\
\hline Never married & 5.6 & 1.1 & 0.9 & 1.4 & 0.3 & 1.0 \\
\hline Married/living together & 29.0 & 2.5 & 24.3 & 9.0 & 31.7 & 3.9 \\
\hline Formerly marrieda & 11.9 & 1.1 & 4.4 & 4.6 & 3.4 & 5.5 \\
\hline \multicolumn{7}{|l|}{ Children ever born } \\
\hline 0 & 0.0 & 0.0 & 0.0 & 0.0 & 0.0 & 0.0 \\
\hline $1-2$ & 28.2 & 3.4 & 29.0 & 11.3 & 33.8 & 7.4 \\
\hline $3-4$ & 27.3 & 2.6 & 26.1 & 9.4 & 37.5 & 4.8 \\
\hline 5 or more & 26.6 & 1.7 & 21.4 & 9.1 & 31.0 & 3.0 \\
\hline \multicolumn{7}{|l|}{ Months since last birth } \\
\hline$<12$ months & 83.6 & 6.4 & 64.4 & 20.6 & 83.6 & 9.1 \\
\hline $12-23$ months & 54.9 & 5.2 & 36.9 & 18.8 & 55.3 & 11.6 \\
\hline 24-35 months & 11.4 & 2.9 & 3.8 & 3.2 & 5.1 & 1.4 \\
\hline 36-47 months & 0.2 & 0.6 & 0.7 & 0.5 & 0.1 & 0.5 \\
\hline 48 months and above & 0.2 & 0.1 & 0.0 & 0.1 & 0.1 & 0.0 \\
\hline \multicolumn{7}{|l|}{$\begin{array}{l}\text { Participation in decision- } \\
\text { makingb }\end{array}$} \\
\hline No & 17.2 & 1.8 & 16.5 & 6.8 & 21.9 & 3.3 \\
\hline Yes & 26.4 & 2.1 & 21.2 & 7.3 & 19.6 & 2.8 \\
\hline
\end{tabular}

aSeparated/divorced/widowed; bAll decisions regarding own health care, making large household purchases, making household purchases for daily needs, visits to family or relatives, and food to be cooked each day; Percentages are weighted 


\section{Breastfeeding status, fertility intentions, and current contraceptive use}

Potential PCVR use may further be influenced by a woman's current postpartum contraceptive needs. Since women's contraceptive uptake is related to resumption of sexual activity, we include only those women who have resumed sexual activity after giving birth.

Figure 13 presents the distribution of women aged 15 to 49 by breastfeeding status, future fertility intentions, resumption of postpartum sexual activity, and current contraceptive use. In Kenya, eight percent of women aged 15 to 49 were breastfeeding four or more times a day, had resumed sexual activity after childbirth, and wanted to delay their next birth by at least one year, or wanted no more children but were using no FP method at the time of the Survey. Meanwhile, seven percent of women in Kenya were breastfeeding four or more times a day, had resumed sexual activity, and either wanted to delay their next birth by at least one year or wanted no more children but were using short-acting or barrier methods. The corresponding figures for Nigeria are 15 percent (not using any method) and two percent (using short-acting or barrier methods); for Sénégal they are 19 percent and two percent, respectively. In all three countries, a small fraction of women were breastfeeding four or more times a day, either wanted to delay the next birth by at least one year or wanted no more children, and were using long-term or permanent methods (0.3\% in Kenya, $0.1 \%$ in Nigeria, and $0.2 \%$ in Sénégal).

\section{FIGURE 13: DISTRIBUTION OF WOMEN AGES 15 TO 49 BY BREASTFEEDING STATUS, FERTILITY INTENTIONS, AND CURRENT CONTRACEPTIVE USE}

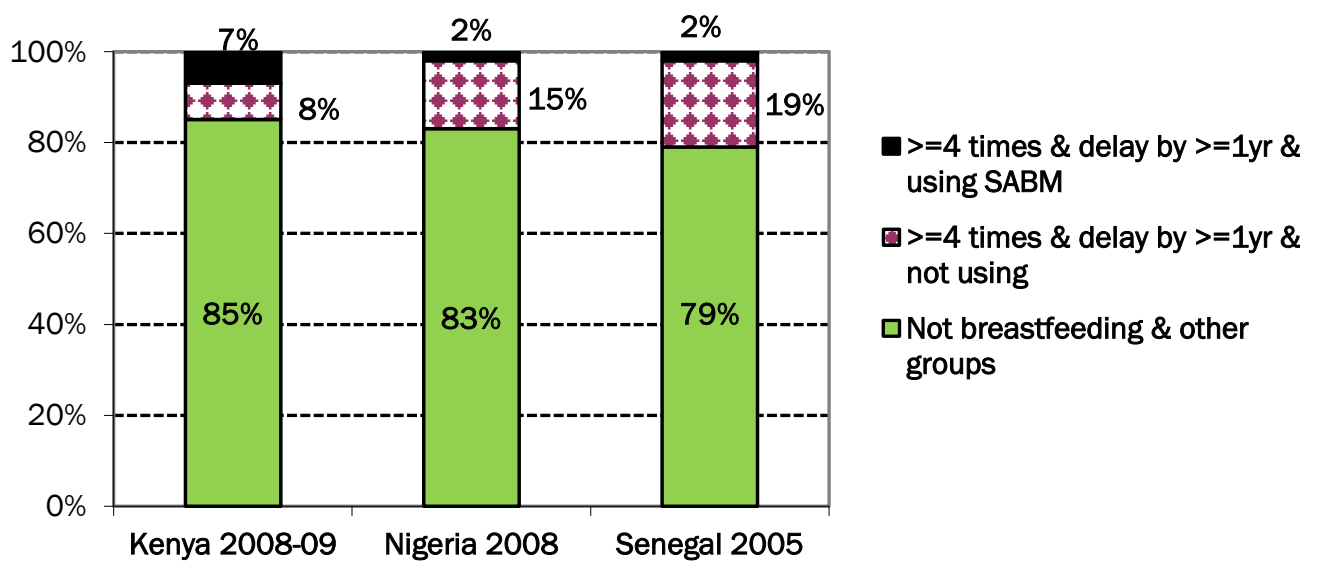

Figure 13 shows, based on dimensions of need and use, that 15 percent of women in Kenya aged 15 to 49 , 17 percent of women of similar ages in Nigeria, and 21 percent of women of similar ages in Sénégal are potential PCVR consumers. Table 2 presents the distribution by background characteristics of women aged 15 to 49 who were breastfeeding four or more times a day, either wanted to delay their next birth by at least one year or wanted no more children, and were either not using a FP method or were using short-acting or barrier methods upon resumption of sexual activity after childbirth. Intra- and cross-country variations in the proportions of such women not using a method are similar to those noted earlier: highest for women aged 20 to 29 , with no education, in the rural areas, married or living with someone, from the poorest households, and with their most recent births within 12 months preceding the Survey, in all the three countries.

By contrast, the proportions of women breastfeeding four or more times daily, wanting either to delay their next birth by at least one year or wanting no more children, and using short-acting or barrier methods were highest among urban Nigerian and Sénégalese women from richer households with secondary or higher educations. In Kenya, this group includes urban as well as rural women in almost equal proportions, with primary educations 
at least and belonging to richer and poorer households. In addition, the proportions of such women were highest in Kenya and Sénégal for women whose last births occurred one to two years preceding the Survey, and in all three countries the women in this group were married or living with someone (Table 2).

TABLE 2: VARIATIONS IN THE PROPORTION OF WOMEN AGES 15 TO 49 BREASTFEEDING FOUR OR MORE TIMES A DAY WHO EITHER WANT TO DELAY THEIR NEXT BIRTH BY ONE OR MORE YEARS OR WANT NO MORE CHILDREN AFTER RESUMING SEXUAL ACTIVITY, BY CONTRACEPTIVE USE ACCORDING TO BACKGROUND CHARACTERISTICS

\begin{tabular}{|c|c|c|c|c|c|c|}
\hline & \multicolumn{2}{|c|}{ Kenya (2008-09) } & \multicolumn{2}{|c|}{ Nigeria (2008) } & \multicolumn{2}{|c|}{ Sénégal (2005) } \\
\hline Characteristics & $\begin{array}{l}\text { Not using } \\
\text { a method }\end{array}$ & $\begin{array}{l}\text { Using } \\
\text { SABM }\end{array}$ & $\begin{array}{l}\text { Not using } \\
\text { a method }\end{array}$ & Using SABM & $\begin{array}{l}\text { Not using } \\
\text { a method }\end{array}$ & $\begin{array}{l}\text { Using } \\
\text { SABM }\end{array}$ \\
\hline \multicolumn{7}{|l|}{ Age (years) } \\
\hline$<20$ years & 3.5 & 0.9 & 7.5 & 0.6 & 7.8 & 0.1 \\
\hline $20-29$ & 11.8 & 10.1 & 20.2 & 3.5 & 26.9 & 2.7 \\
\hline $30-39$ & 9.6 & 8.6 & 18.1 & 3.3 & 26.3 & 3.5 \\
\hline $40-49$ & 2.9 & 2.3 & 6.6 & 0.7 & 8.4 & 1.3 \\
\hline \multicolumn{7}{|l|}{ Highest education level } \\
\hline No schooling & 13.9 & 3.4 & 21.5 & 0.9 & 24.7 & 1.5 \\
\hline Primary & 10.1 & 7.3 & 17.2 & 3.0 & 14.7 & 2.9 \\
\hline Secondary & 3.3 & 6.8 & 9.0 & 3.2 & 6.1 & 2.9 \\
\hline Higher & 1.9 & 2.9 & 5.3 & 3.8 & 1.2 & 1.3 \\
\hline \multicolumn{7}{|l|}{ Place of residence } \\
\hline Urban & 3.8 & 5.7 & 10.0 & 3.6 & 12.0 & 2.9 \\
\hline Rural & 9.5 & 6.8 & 17.4 & 1.7 & 26.2 & 1.3 \\
\hline \multicolumn{7}{|l|}{ Wealth quintile } \\
\hline Poorest quintile & 17.4 & 5.0 & 22.2 & 1.0 & 31.4 & 0.9 \\
\hline Poorer quintile & 10.0 & 7.3 & 19.7 & 1.0 & 26.3 & 1.1 \\
\hline Middle quintile & 6.2 & 6.7 & 15.1 & 1.8 & 21.8 & 2.1 \\
\hline Richer quintile & 6.1 & 7.1 & 11.8 & 2.8 & 14.1 & 3.1 \\
\hline Richest quintile & 3.7 & 6.3 & 7.1 & 4.8 & 8.7 & 2.6 \\
\hline \multicolumn{7}{|l|}{ Marital status } \\
\hline Never married & 0.9 & 0.2 & 0.8 & 0.2 & 0.3 & 0.0 \\
\hline Married/living together & 12.5 & 10.8 & 20.4 & 3.3 & 28.1 & 3.0 \\
\hline Formerly marrieda & 4.1 & 1.2 & 4.3 & 0.1 & 3.2 & 0.0 \\
\hline \multicolumn{7}{|l|}{ Children ever born } \\
\hline 0 & 0.0 & 0.0 & 0.0 & 0.0 & 0.0 & 0.0 \\
\hline $1-2$ & 9.2 & 9.5 & 24.0 & 4.4 & 13.0 & 3.2 \\
\hline $3-4$ & 11.4 & 9.8 & 21.1 & 4.4 & 33.2 & 3.7 \\
\hline 5 or more & 13.1 & 7.3 & 18.8 & 2.0 & 27.7 & 2.8 \\
\hline \multicolumn{7}{|l|}{ Months since last birth } \\
\hline$<12$ months & 32.2 & 18.3 & 54.5 & 8.2 & 76.6 & 5.4 \\
\hline $12-23$ months & 22.9 & 26.1 & 30.5 & 5.8 & 46.4 & 8.3 \\
\hline $24-35$ months & 5.6 & 5.7 & 3.2 & 0.4 & 4.7 & 0.3 \\
\hline $36-47$ months & 0.2 & 0.0 & 0.7 & 0.0 & 0.1 & 0.0 \\
\hline 48 months and above & 0.2 & 0.0 & 0.0 & 0.0 & 0.1 & 0.0 \\
\hline \multicolumn{7}{|l|}{$\begin{array}{l}\text { Participation in decision- } \\
\text { making }\end{array}$} \\
\hline No & 7.2 & 4.3 & 14.4 & 1.9 & 19.5 & 2.0 \\
\hline Yes & 10.1 & 11.8 & 16.2 & 4.2 & 16.7 & 2.6 \\
\hline & & & & & & \\
\hline
\end{tabular}

aSeparated/divorced/widowed; bAll decisions regarding own health care, making large household purchases, making household purchases for daily needs, visits to family or relatives, and food to be cooked each day; SABM: Short-acting or barrier method; percentages are weighted 


\section{Simulated potential PCVR uptake scenarios}

Table 3 presents the results of analysis involving the estimation of potential PCVR use by looking at women of reproductive age who breastfed less than four times a day (i.e. less than the recommended breastfeeding frequency for PCVR use) and other non-breastfeeding women of reproductive age who would have a potential need for the PCVR in the future. These groups of women were considered to have a future need for the PCVR if they intended to have children and use a method of contraception in the future for either spacing or limiting births, if not using one currently. Even though they are not part of the direct and immediate PCVR market, they are vital for forecasting potential use and creating a sustainable consumer base for the PCVR. We used various uptake levels (a conservative 5\%, moderate 10\% and optimistic 15\% and an ideal 20\%) to forecast PCVR use estimates for this potential consumer group.

In all three countries, no substantial change in potential method users would occur if only women who breastfed less than the required frequency (minimum 4 times a day) were targeted. Assuming that five percent of these women use the method in future, potential PCVR use would remain unchanged in all three countries (15\% in Kenya, 17\% in Nigeria and 21\% in Sénégal). It can be seen that even under the other uptake scenarios of $10 \%, 15 \%$ and the ideal $20 \%$, potential PCVR use by these women would remain unchanged in all three countries. By contrast, potential PCVR use would increase if women breastfeeding less than four times a day as well as those not breastfeeding but with future intent to bear children and use contraception are targeted. If five percent of such women use the method, use estimates would increase by one percentage point in all three countries (16\% in Kenya, 18\% in Nigeria and 22\% in Sénégal). Similarly, if 20 percent of such women use the method, potential PCVR use would increase by four percentage points in Kenya and three percent each in Nigeria and Sénégal (19\% in Kenya, 20\% in Nigeria and 24\% in Sénégal).

\section{TABLE 3: ESTIMATES OF POTENTIAL PCVR USE WITH SIMULATED UPTAKE SCENARIOS}

\begin{tabular}{|c|c|c|c|}
\hline Potential PCVR market & $\begin{array}{c}\text { Kenya } \\
(2008-09)\end{array}$ & $\begin{array}{l}\text { Nigeria } \\
(2008)\end{array}$ & $\begin{array}{l}\text { Sénégal } \\
\text { (2005) }\end{array}$ \\
\hline Estimates based on dimensions of need and use & $15 \%$ & $17 \%$ & $21 \%$ \\
\hline \multicolumn{4}{|l|}{ Estimates based on dimensions of need and use as well as uptake of $5 \%$} \\
\hline Women breastfeeding less than 4 times a day with future contraceptive need* & $15 \%$ & $17 \%$ & $21 \%$ \\
\hline $\begin{array}{l}\text { Women breastfeeding less than } 4 \text { times a day as well as non-breastfeeding } \\
\text { women with future contraceptive need* }\end{array}$ & $16 \%$ & $18 \%$ & $22 \%$ \\
\hline \multicolumn{4}{|l|}{ Estimates based on dimensions of need and use as well as uptake of $10 \%$} \\
\hline Women breastfeeding less than 4 times a day with future contraceptive need* & $15 \%$ & $17 \%$ & $21 \%$ \\
\hline $\begin{array}{l}\text { Women breastfeeding less than } 4 \text { times a day as well as non-breastfeeding } \\
\text { women with future contraceptive need* }\end{array}$ & $17 \%$ & $18 \%$ & $23 \%$ \\
\hline \multicolumn{4}{|l|}{ Estimates based on dimensions of need and use as well as uptake of $15 \%$} \\
\hline Women breastfeeding less than 4 times a day with future contraceptive need* & $15 \%$ & $17 \%$ & $21 \%$ \\
\hline $\begin{array}{l}\text { Women breastfeeding less than } 4 \text { times a day as well as non-breastfeeding } \\
\text { women with future contraceptive need* }\end{array}$ & $18 \%$ & $19 \%$ & $23 \%$ \\
\hline \multicolumn{4}{|l|}{ Estimates based on dimensions of need and use as well as uptake of $20 \%$} \\
\hline Women breastfeeding less than 4 times a day with future contraceptive need* & $15 \%$ & $17 \%$ & $21 \%$ \\
\hline $\begin{array}{l}\text { Women breastfeeding less than } 4 \text { times a day as well as non-breastfeeding } \\
\text { women with future contraceptive need* }\end{array}$ & $19 \%$ & $20 \%$ & $24 \%$ \\
\hline
\end{tabular}

*Non-breastfeeding and women breastfeeding less than four times a day who intend to have children, may not currently be using a method, but intend to use a method in the future were considered to have future need for contraception. 


\section{Results}

Analysis of the secondary DHS data, utilizing the needs-based market segmentation framework, provides a high measure of understanding consumers' needs for PPFP, with three broad levels of need-partial, complete and potential. From these three levels of need, three unique market segments result:

1. Easy Switchers (with partial need)

2. Remote First-timers (with complete need)

3. Growth Feeders (with potential need)

\section{FIGURE 14: PCVR MARKET SEGMENTS}

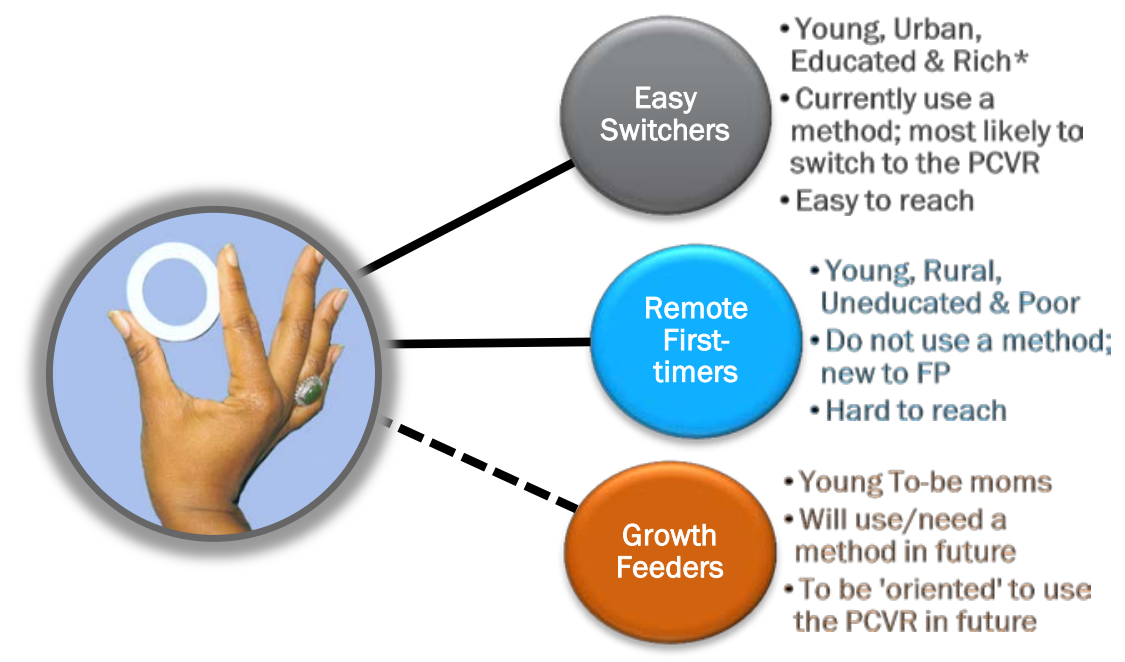

*In Kenya, 'Easy Switchers' include almost equal proportions of urban and rural women from the poorer and richer quintiles

\section{MARKET SEGMENTS FOR THE PROGESTERONE CONTRACEPTIVE VAGINAL RING}

The three market segments each have unique attributes-socio-economic, cultural, and demographic:

Easy Switchers are educated and urban, aged 20 to 29, from high wealth quintiles, who are able to make independent FP decisions and are aware of their country's available method mix. These educated women are looking for a safe and convenient postpartum method to space or limit births that also suits their lifestyle, and PCVR's safety coupled with its control by individual women will satisfy their PPFP needs. Although they are already PPFP users, they are most likely to be PCVR early adopters, willing to switch upon its introduction. Since they already are method users, they have a 'partial' need for a new PPFP method. While this segment includes urban, affluent contraceptive users exclusively in Nigeria and Sénégal, in Kenya this segment includes almost equal proportions of urban and rural women (as suggested by the high contraceptive prevalence) from the poorer and richer quintiles.

Remote First-timers include uneducated, hard-to-reach, rural women aged 20 to 29 from the poorest households, who have never used a PPFP method. As the neediest women among the three segments looking for ways to space pregnancies and avoid unintended pregnancies, they either don't have access to health facilities or are simply unaware of available FP options. To some extent, they depend upon family members and their communities for their FP decisions. Since they do not currently use a FP method, they represent the segment with 'complete' need for a new PPFP method like the PCVR. 
Growth Feeders include non-breastfeeding women (women over 25 with or without children) as well as the youngest women of reproductive age (15 to 25 years old) with future PPFP need (intending to bear children and use contraception in the future, if not using currently). This consumer group has a 'potential' or 'hidden' need for PPFP, in the future. While not part of the immediate PCVR market, these women are vital for forecasting potential use and creating a sustainable consumer base: These women are a potential growth segment. Taking advantage of the fact that education and exposure to FP messages play major roles in contraceptive use, targeting this segment for creating and promoting sustainable PCVR demand is important.

\section{PCVR marget segment sizes in Kenya, Nigeria, and Sénégal}

\section{TABLE 4: ESTIMATES OF ANNUAL USE FOR EACH MARKET SEGMENT IN KENYA, NIGERIA, AND SÉNÉGAL}

\begin{tabular}{|c|c|c|c|}
\hline Segment & Kenya & Nigeria & Sénégal \\
\hline Easy Switchers & $7 \%$ (0.8 million) & $2 \%$ (0.8 million) & $2 \%(69,000)$ \\
\hline Remote First-timers & $8 \%$ (0.9 million) & $15 \%$ (6.1 million) & $19 \%$ (0.7 million) \\
\hline Growth Feeders* & $2 \%$ (0.2 million) & $1 \%$ (0.4 million) & $2 \%(69,000)$ \\
\hline Total & $17 \%$ & $18 \%$ & $23 \%$ \\
\hline
\end{tabular}

Percent of women of reproductive age (15 to 49) who are likely PCVR consumers, annual estimate; *10\% PCVR uptake estimate

Easy Switchers are easy to target and represent a potential PCVR user base of seven percent in Kenya and two percent each in Nigeria and Sénégal, comprising approximately 800,000 women in both Kenya and Nigeria, and 69,000 women in Sénégal each year.

Hard-to-reach Remote First-timers also present a huge opportunity for PCVR with eight percent in Kenya (0.9 million women), 15 percent in Nigeria (6.1 million women), and 19 percent in Sénégal (0.7 million women) each year. However, a rigorous marketing plan complete with active promotional campaigns and access strategies is necessary for realizing the opportunity presented by this group.

The third segment, Growth Feeders, is vital for generating a sustainable PCVR consumer base. Using a moderate PCVR uptake estimate of 10 percent, we arrive at potential segment size of two percent in Kenya, one percent in Nigeria, and two percent in Sénégal that translates to roughly 200,000 women in Kenya, 400,000 women in Nigeria, and 69,000 women in Sénégal each year. Under a 20 percent uptake scenario, we can potentially expect 400,000 women in Kenya, 1.2 million women in Nigeria, and 100,000 women in Sénégal to join the PCVR consumer base every year. This strongly indicates the need for robust marketing campaigns to nurture and educate the Growth Feeders to create a sustainable PCVR demand.

These three segments demonstrate the opportunity available for multiple players in PCVR's mode of introduction. In addition to program managers a wider group of stakeholders including the public sector (MoH), procurers (government and donors), and private sector (non-profit and commercial) can benefit from this exercise and identify their segments of interest and tailor specific strategies. 


\section{Discussion and Next Steps}

The three market segments identified for the PCVR market in Kenya, Nigeria, and Sénégal present a consumercentric view of the opportunity available for PCVR's introduction in those countries.

\section{POSSIBLE STRATEGIES FOR SERVING THE PCVR MARKET SEGMENTS}

Based on the segment profiles, we can suggest a set of possible strategies to serve these individual segments and identify opportunities for the three sectors-public, private non-profit, and private commercial-to engage in PCVR's introduction.

Easy Switchers represent a straightforward targeting strategy. These urban, educated, and affluent FP users present the ideal opportunity for PCVR introduction with minimal burden on marketing resources, as they can be easily reached with technology such as mobile phones and other media channels. They also will be the ones most likely to influence the mode of introduction of PCVR to the method mix with their ability and willingness to pay for PPFP. They can be potentially served by the private non-profit or private commercial sectors. While this segment exclusively includes the urban, rich women in Nigeria and Sénégal, it is important to note that in Kenya, this segment includes an almost equal proportion of women from urban and rural areas (as suggested by the high contraceptive prevalence) split between poorer and richer quintiles. While the rich urban or rural dwellers among them can be served by the private commercial sector, the rural as well urban poor have to be served by the public and the private non-profit sectors. This also underscores the vital role of the Kenyan public sector in responding to the rapidly growing segment of poor urban women ${ }^{7}$ with FP needs.

Remote First-timers require an extensive marketing strategy complete with compelling awareness campaigns and effective access strategies. These hard-to-reach rural women demand a systematic marketing approach with effective product messaging and access solutions. The strong unmet need demonstrated by this segment will help justify the marketing investment and maximum allocation of resources. They will also prompt the active involvement of the public sector and private non-profit sectors to implement price subsidization or explore innovative financing methods for the PCVR. Further, the fact that PCVR is entirely woman-controlled, thereby reducing the dependency on medical providers and the need for significant health system infrastructure for service delivery, can greatly reduce some of the access barriers faced by these women.

The finding that PCVR's uptake is likely to increase regardless of CPR if both breastfeeding and nonbreastfeeding women are targeted (Growth Feeders segment) suggests that the potential PCVR consumer base is likely to widen with appropriate awareness campaigns. Further, the population dynamics in these three countries highlight the growing opportunity available for the Growth Feeders segment. The rising growth rate of the youth population coupled with rapid urbanization in Kenya, Nigeria and Sénégal indicates a potential surge in educated, first-time mothers who might be more receptive to new health technologies such as the PCVR than mothers from the previous generations and who can also be easily reached with suitable access strategies. This also indicates the potential opportunity available for all the three sectors-public, private nonprofit, and private commercial-to design innovative promotional strategies to nurture this growth segment, including educating them about FP options available throughout the reproductive life cycle of a woman and highlighting the positioning of PCVR in the postpartum phase. Catering to this segment will help empower young women to space their pregnancies safely and reduce chances of unintended pregnancies and abortion risks. Further, it enables the promotion of healthy postpartum care and breastfeeding practices according to WHO guidelines. Learning more about the needs and attributes of this group, will help in PCVR product positioning and messaging. From a program management perspective, analyzing this segment's PPFP needs is important for addressing key decisions pertaining to the public sector-to devise effective procurement plans and assess government's resource planning to facilitate future PCVR uptake.

\footnotetext{
$770 \%$ of Kenya's urban dwellers live in slums, and urban poverty will represent almost half of Kenya's total poverty by 2020 ;
} Source: World Bank estimates. 
While analysis of cost barriers to contraceptive use is beyond the scope of this analysis, the three segments' demographics indicate that PCVR's access may be influenced by cost. While cost may not be a major barrier to the method for affluent, urban Easy Switchers, it can be a large barrier for poor, rural Remote First-timers.

As potential next steps, we intend to build on this market segmentation exercise by identifying levers for promoting PCVR use from public or private sources, whichever is best suited to serve these individual segments. We will work on supplementing this exercise with the results from the ongoing PCVR acceptability studies in the three countries as well as other planned studies including one assessing consumers' Willingness to Pay, which will provide more insights into PCVR consumer behavior-their lifestyles, beliefs, and attitudes-to help build the consumer profiles and obtain realistic PCVR demand estimates. Along with this information, further enhancements may include a more robust PCVR demand forecasting using detailed country UNFPA population projections and analyzing the growth trends of the three country's urban and rural populations ${ }^{8}$.

With this factual foundation, we can design our next steps to inform and assess the role of the different sectors-public, private non-profit, and private commercial-and define the comparative advantages of each for their efficiency in delivering services to these market segments. This market segmentation exercise provides an initial means for implementing a Total Market Approach for PCVR's introduction strategy.

\section{LIMITATIONS OF THIS ANALYSIS}

The analysis for this market segmentation exercise hinges on a number of assumptions. First, it is assumed that the indicators of need and use have not substantially changed since the last DHS ${ }^{9}$. The DHS data used in this analysis were collected approximately five years preceding this report, and some indicators of service need and use may have changed. Analysis of five year trends for selected indicators, such as TFR, CPR, unmet FP need, and median duration of exclusive breastfeeding (in months), indicates substantial increases for CPR only in Kenya (Table 7, Appendix 3), while the country's other indicators demonstrate modest changes. All of the indicators for Nigeria and Sénégal demonstrate modest improvements for the five year period (Table 7). These generally modest increases for all three countries suggest that it is appropriate to assume their indicators of need and use have not changed much since the last DHS. This analysis can, however, be periodically reviewed and revised as new DHS data are available for the three countries.

This analysis excludes consideration of the cost barrier of the PCVR for assessing its potential use. While the segment profiles clearly indicate that the initial cost for obtaining the method may be high for most women without subsidies, insights from planned WTP studies will help design affordable pricing strategies for effectively addressing PCVR's cost barrier.

The third assumption is that myths and misconceptions do not pose major barriers to PCVR use. To the extent that the assumption does not hold, the estimated potential use for the method is an over-estimate. It is further assumed that women who want to space the next pregnancy by more than one year might use PCVR during the first year and switch to other methods thereafter. While women looking to limit their births can also use PCVR during their first postpartum year and then switch to permanent methods.

Finally, the analysis uses secondary data to define potential PCVR consumers. A limitation of the secondary data, however, is that they do not capture certain information crucial for market size estimation, such as all factors likely to influence use of the method such as costs, myths, and misconceptions. Although market segmentation research can be completed using only secondary data, if time and funding allow, this study can be more comprehensive if primary data are collected. While market segmentation research is not designed to shape the market, it can reveal the underlying divisions in the market and characteristics of the market segments that help inform the overall marketing strategy. This exercise is intended to let us mimic the 'real time' market analysis and plan for activities to ensure successful PCVR introduction.

\footnotetext{
8 Kenya's urban population has grown at 5\% over the last decade, much faster than the average increase for sub-Saharan Africa; annual urban population growth in Nigeria and Sénégal was last measured at 3.97\% and 3.27\%, respectively, in 2010; Source: World Bank.

9 This report uses Kenya DHS 2008-09, Nigeria 2008, and Sénégal 2005.
} 


\section{References}

Ali, M.M., J. Cleland and I. Shah. 2012. Causes and consequences of contraceptive discontinuation: Evidence from 60 demographic and health surveys. Geneva: WHO.

ANSD [Agence Nationale de la Statistique et de la Démographie] and ICF International. 2012. Enquête Démographique et de Santé à Indicateurs Multiples au Sénégal (EDS-MICS) 2010-2011. Calverton, MD: ANSD et ICF International.

Bahamondes, L. 2008. Interventions Subdermal implantable contraceptives versus other forms of reversible contraceptives or other implants as effective methods of preventing pregnancy: RHL commentary. Geneva: WHO Reproductive Health Library (RHL).

Berg, R. 2000. Initiating public/private partnerships to finance reproductive health: The role of market segmentation analysis. USAID POLICY Working Paper Series 7. Washington, DC: USAID.

Blumenthal, P.D., A. Voedisch and K. Gemzell-Danielsson. 2011. Strategies to prevent unintended pregnancy: increasing use of long acting reversible contraception. Human Reproduction Update 17(1): 121-137.

Borda, M. and W. Winfrey. 2010. Postpartum fertility and contraception: Analysis of findings from 17 countries. Baltimore: Jhpiego.

Borda, M. and W. Winfrey. 2006. Family planning needs during the extended postpartum period in Nigeria. Baltimore: Jhpiego.

Bradley, S.K., H.M. Schwandt and S. Khan. 2009. Levels, trends and reasons for contraceptive discontinuation. DHS Analytical Studies 20. Calverton, MD: ICF Macro.

Campbell, M., N.N. Sahin-Hodoglugil and M. Potts. 2006. Barriers to fertility regulation: A review of the literature. Studies in Family Planning 37(2): 87-98.

CBS [Central Bureau of Statistics, MoH [Ministry of Health], and ORC Macro. 2004. Kenya Demographic and Health Survey 2003. Calverton, MD: CBS, MoH, and ORC Macro.

Cleland, J., S. Bernstein, A. Ezeh, A. Faundes, A. Glasier and J. Innis. 2006. Family planning: The unfinished agenda. The Lancet 368: 1810-1827.

Darroch, J.E., G. Sedgh and H. Ball. 2011. Contraceptive technologies: Responding to women's needs. New York: Guttmacher Institute.

DRH [Division of Reproductive Health]/MoPHS [Ministry of Public Health and Sanitation]. 2010. National Family Planning Guidelines for Service Providers. Nairobi: DRH/MoPHS.

Gebreselassie, T., S.O. Rutstein and V. Mishra. 2008. Contraceptive use, breastfeeding, amenorrhea and abstinence during the postpartum period: An analysis of four countries. DHS Analytical Studies 14. Calverton, MD: Macro International, Inc.

Ishaku, S. and S. RamaRao. 2012. Progesterone vaginal ring country mapping: Nigeria. New York: Population Council.

KNBS [Kenya National Bureau of Statistics]. 2010. 2009 Kenya Population and Housing Census $1 \mathrm{~A} \& 1 \mathrm{C}$. Nairobi: KNBS.

KNBS [Kenya National Bureau of Statistics] and ICF Macro. 2010. Kenya Demographic and Health Survey 2008-09. Calverton, MD: KNBS and ICF Macro.

Mané, B., N. Diop, N. Termini, S. RamaRao and H. Clark. 2012. Progesterone vaginal ring country mapping: Sénégal. New York: Population Council. 
Market Development Approaches Working Group. 2009. Market segmentation primer. Cambridge: Abt Associates.

Massai, R., E. Quinteros, M.V. Reyes, R. Caviedes, A. Zepeda, J.C. Montero and H.B. Croxatto. 2005. Extended use of a progesterone-releasing vaginal ring in nursing women: A phase II clinical trial. Contraception 72: $352-$ 357.

Massai, R., S. Díaz, T. Jackanicz and H.B. Croxatto. 2000. Vaginal rings for contraception in lactating women. Steroids 65: 703-707.

Massai, R., P. Miranda, P. Valdés, P. Lavín, A. Zepeda, M.E. Casado, M.A. Silva, G. Fetis, C. Bravo, O. Chandía, O. Peralta, H.B. Croxatto and S. Díaz. 1999. Preregistration study on the safety and contraceptive efficacy of a progesterone-releasing vaginal ring in Chilean nursing women. Contraception 60: 9-14.

Nath, A. and R. Sitruk-Ware. 2010. Progesterone vaginal ring for contraceptive use during lactation. Contraception 82: 428-434.

Ndiaye, S. and M. Ayad. 2006. Enquête Démographique et de Santé au Sénégal 2005. Calverton, Maryland, USA: Centre de Recherche pour le Développement Humain [Sénégal] et ORC Macro.

NPC [National Population Commission] and ICF Macro. 2009. Nigeria Demographic and Health Survey 2008. Abuja: National Population Commission and ICF Macro.

NPC [National Population Commission] and ORC Macro. 2004. Nigeria Demographic and Health Survey 2003. Calverton, Maryland: National Population Commission and ORC Macro.

Obare, F., W. Liambila, H. Birungi, E. Itombra, H. Clark and S. RamaRao. 2012. Progesterone vaginal ring country mapping: Kenya. New York: Population Council.

RHSC [Reproductive Health Supplies Coalition]. 2011. Progesterone-only vaginal ring: Product brief. Brussels: RHSC.

Ross J. and W. Winfrey. 2001. Contraceptive use, intention to use and unmet need during the extended postpartum period. International Family Planning Perspectives 27(1): 20-27.

Singh, S. and J.E. Darroch. 2012. Adding it up: Costs and benefits of contraceptive services-estimates for 2012. New York: Guttmacher Institute and United Nations Population Fund (UNFPA).

Singh, S., J.E. Darroch, L.S. Ashford and M. Vlassoff. 2009. Adding it up: the costs and benefits of investing in family planning and maternal and newborn health. New York: Guttmacher Institute and UNFPA.

Sivin, I., S. Díaz, H.B. Croxatto, P. Miranda, M. Shaaban, E.H. Sayed, B. Xiao, S.C. Wu, M.K. Du, F. Alvarez, V. Brache, S. Basnayake, T. McCarthy, M. Lacarra, D.R. Mishell, S. Koetsawang, J. Stern and T. Jackanicz. 1997. Contraceptives for lactating women: A comparative trial of progesterone-releasing vaginal ring and Copper T380A IUD. Contraception 55: 225-232.

Smith, R., L. Ashford, J. Gribble and D. Clifton. 2009. Family planning saves lives. Fourth Edition. Washington, DC: Population Reference Bureau.

UNDESA [United Nations Department of Economic and Social Affairs]. 2012. World population prospects: The 2012 revision. http://esa.un.org/wpp/unpp/panel_population.htm [accessed May 22, 2013].

WHO. 2012. From evidence to policy: Expanding access to family planning-strategies to increase use of longacting and permanent contraception. Geneva: WHO. 


\section{APPENDIX 1}

\section{TABLE 5: PERCENT DISTRIBUTION BY BACKGROUND CHARACTERISTICS OF WOMEN AGES 15 TO 49 IN KENYA, NIGERIA, AND SÉNÉGAL}

\begin{tabular}{|c|c|c|c|}
\hline Characteristics & $\begin{array}{c}\text { Kenya, 2008-09 } \\
(\%)\end{array}$ & $\begin{array}{c}\text { Nigeria, } 2008 \\
(\%)\end{array}$ & $\begin{array}{c}\text { Sénégal, } 2005 \\
(\%)\end{array}$ \\
\hline \multicolumn{4}{|l|}{ Age (years) } \\
\hline$<20$ years & 20.9 & 19.5 & 24.4 \\
\hline $20-29$ & 37.5 & 37.3 & 35.8 \\
\hline $30-39$ & 24.7 & 25.6 & 24.4 \\
\hline $40-49$ & 16.9 & 17.7 & 15.5 \\
\hline \multicolumn{4}{|l|}{ Highest education level } \\
\hline No schooling & 8.9 & 35.8 & 59.6 \\
\hline Primary & 56.8 & 19.7 & 25.2 \\
\hline Secondary & 26.9 & 35.7 & 14.2 \\
\hline Higher & 7.4 & 8.9 & 1.0 \\
\hline \multicolumn{4}{|l|}{ Place of residence } \\
\hline Urban & 25.4 & 35.8 & 48.7 \\
\hline Rural & 74.6 & 64.3 & 51.3 \\
\hline \multicolumn{4}{|l|}{ Wealth quintile } \\
\hline Poorest quintile & 16.5 & 18.6 & 16.7 \\
\hline Poorer quintile & 17.6 & 18.7 & 17.6 \\
\hline Middle quintile & 19.1 & 19.0 & 19.4 \\
\hline Richer quintile & 20.6 & 20.8 & 21.6 \\
\hline Richest quintile & 26.3 & 23.0 & 24.7 \\
\hline \multicolumn{4}{|l|}{ Marital status } \\
\hline Never married & 31.2 & 25.2 & 27.0 \\
\hline Married/living together & 58.4 & 70.6 & 67.6 \\
\hline Formerly marrieda & 10.4 & 4.2 & 5.5 \\
\hline \multicolumn{4}{|l|}{ Children ever born } \\
\hline 0 & 27.5 & 29.9 & 35.6 \\
\hline $1-2$ & 28.3 & 21.5 & 23.1 \\
\hline $3-4$ & 22.1 & 19.5 & 16.4 \\
\hline 5 or more & 22.2 & 29.1 & 25.0 \\
\hline All women & 100.0 & 100.0 & 100.0 \\
\hline Number of women & 8,444 & 33,385 & 14,602 \\
\hline
\end{tabular}




\section{APPENDIX 2}

\section{TABLE 6: VARIATIONS IN BREASTFEEDING STATUS BY BACKGROUND CHARACTERISTICS AMONG WOMEN AGES 15 TO 49 IN KENYA, NIGERIA, AND SÉNÉGAL}

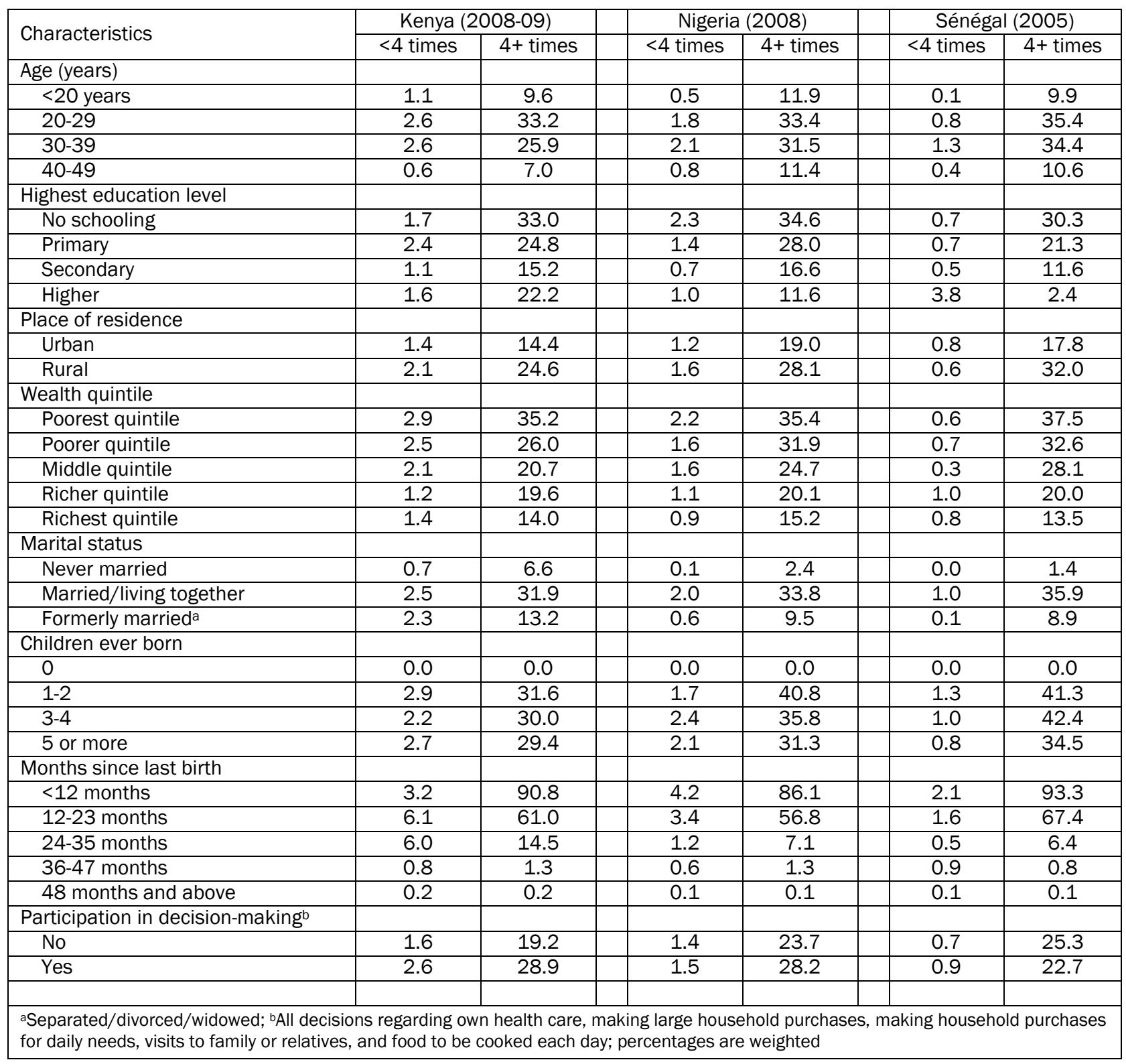




\section{APPENDIX 3}

\section{TABLE 7: FIVE YEAR TRENDS IN SELECTED INDICATORS FOR KENYA, NIGERIA, AND SÉNÉGAL}

\begin{tabular}{|c|c|c|c|c|}
\hline Country and Survey year & Total fertility rate & $\begin{array}{c}\text { Contraceptive } \\
\text { prevalence rate } \\
(\%)\end{array}$ & $\begin{array}{c}\text { Unmet need for } \\
\text { family planning (\%) }\end{array}$ & $\begin{array}{c}\text { Median duration of } \\
\text { exclusive breastfeeding } \\
\text { (months) }\end{array}$ \\
\hline Kenya & & & & \\
\hline 2003 & 4.9 & $39 \%$ & $27 \%$ & 0.5 \\
\hline $2008-09$ & 4.6 & $46 \%$ & & 0.7 \\
\hline Nigeria & & & $18 \%$ & 0.5 \\
\hline 2003 & 5.7 & $13 \%$ & $20 \%$ & 0.5 \\
\hline 2008 & 5.7 & $15 \%$ & & \\
\hline Sénégal & & & $32 \%$ & 1.2 \\
\hline 2005 & 5.3 & $12 \%$ & $30 \%$ & 1.6 \\
\hline $2010-11$ & 5.0 & $13 \%$ & & \\
\hline
\end{tabular}

Sources: NPC and ORC Macro 2004; CBS, MoH and ORC Macro 2004; Ndiaye and Ayad 2006; NPC and ICF Macro 2009; KNBS and ICF Macro 2010; ANSD and ICF International 2012 
BILL \& MELINDA GATES foundation
One Dag Hammarskjold Plaza New York, NY 10017

popcouncil.org 